\title{
Monitoring LAI, Chlorophylls, and Carotenoids Content of a Woodland Savanna Using Hyperspectral Imagery and 3D Radiative Transfer Modeling
}

\author{
Thomas Miraglio ${ }^{1,2, *}$, Karine Adeline ${ }^{1}$, Margarita Huesca ${ }^{3}$, Susan Ustin ${ }^{3}$ \\ and Xavier Briottet ${ }^{1}$ (D) \\ 1 ONERA/DOTA, Université de Toulouse, F-31055 Toulouse, France; karine.adeline@onera.fr (K.A.); \\ xavier.briottet@onera.fr (X.B.) \\ 2 Université Fédérale Toulouse Midi-Pyrénées, 41 Allées Jules Guesde, 31013 Toulouse, France \\ 3 Dept. Land, Air and Water Resources, University of California, Davis, One Shield Avenue, Davis, CA 95616, \\ USA; mhuescamartinez@ucdavis.edu (M.H.); slustin@ucdavis.edu (S.U.) \\ * Correspondence: thomas.miraglio@onera.fr
}

Received: 28 October 2019; Accepted: 15 December 2019; Published: 19 December 2019

\begin{abstract}
Leaf pigment contents, such as chlorophylls $a$ and $b$ content $\left(\mathrm{C}_{a b}\right)$ or carotenoid content (Car), and the leaf area index (LAI) are recognized indicators of plants' and forests' health status that can be estimated through hyperspectral imagery. Their measurement on a seasonal and yearly basis is critical to monitor plant response and adaptation to stress, such as droughts. While extensively done over dense canopies, estimation of these variables over tree-grass ecosystems with very low overstory LAI (mean site LAI $<1 \mathrm{~m}^{2} / \mathrm{m}^{2}$ ), such as woodland savannas, is lacking. We investigated the use of look-up table (LUT)-based inversion of a radiative transfer model to retrieve LAI and leaf $\mathrm{C}_{a b}$ and Car from AVIRIS images at an $18 \mathrm{~m}$ spatial resolution at multiple dates over a broadleaved woodland savanna during the California drought. We compared the performances of different cost functions in the inversion step. We demonstrated the spatial consistency of our LAI, $\mathrm{C}_{a b}$, and Car estimations using validation data from low and high canopy cover parts of the site, and their temporal consistency by qualitatively confronting their variations over two years with those that would be expected. We concluded that LUT-based inversions of medium-resolution hyperspectral images, achieved with a simple geometric representation of the canopy within a 3D radiative transfer model (RTM), are a valid means of monitoring woodland savannas and more generally sparse forests, although for maximum applicability, the inversion cost functions should be selected using validation data from multiple dates. Validation revealed that for monitoring use: The normalized difference vegetation index (NDVI) outperformed other indices for LAI estimations (root mean square error $\left(\right.$ RMSE) $\left.=0.22 \mathrm{~m}^{2} / \mathrm{m}^{2}, R^{2}=0.81\right)$; the band ratio $\frac{\rho_{0.750 \mu \mathrm{m}}}{\rho_{0.550 \mu \mathrm{m}}}$ retrieved $\mathrm{C}_{a b}$ more accurately than other chlorophylls indices (RMSE $=5.21 \mu \mathrm{g} / \mathrm{cm}^{2}, R^{2}=0.73$ ); RMSE over the $0.5-0.55 \mu \mathrm{m}$ interval showed encouraging results for Car estimations.
\end{abstract}

Keywords: AVIRIS; DART; leaf pigments; Mediterranean forest; tree-grass ecosystem

\section{Introduction}

The Mediterranean-like ecoregions are expected to face the greatest proportional change in their biodiversity by 2100 because of climate change [1]. These ecoregions (Mediterranean Basin, California, Chile, South Africa and Western Australia) are characterized by hot and dry summers, cool and wet winters, and a large annual rainfall variability. They present a high plant and animal diversity spread within numerous vegetation types [2]. Mediterranean forests in particular range from dense forests 
to dehesa pastures, with trees scattered over a grass field. They notably display a high proportion of broadleaved species compared to forests found in northern parts of Europe [2]. While plants have adapted to this climate, the Mediterranean biome is still one of the most imperilled, as increased frequency of heat and drought periods as well as growing anthropogenic pressure are threatening the present equilibrium [3-5]. To identify key threats and guide forest conservation efforts, it is crucial to understand disturbance regimes, species adaptability, and ecological processes [6]: An improved monitoring of the ecoregions is therefore necessary. Essential biodiversity variables (EBVs) have been recently conceptualized by the Biodiversity Observation Network of the Group on Earth Observations (GEOBON) to unify the global monitoring efforts [7,8]. Foliar pigment contents (such as chlorophylls $\mathrm{a}+\mathrm{b}$ content $\mathrm{C}_{a b}$, carotenoids content Car) and leaf area index (LAI) have been identified as traits associated with the ecosystem structure and its relationship to biodiversity. Indeed, leaf pigments are involved in the photosynthetic process, leaf protection, and also contribute to the ecosystem's biogeochemical and nutrient cycles [9-11], while LAI controls many biological and physical processes such as gross primary production (GPP), rainfall interception, and heat fluxes [12]. Estimating these variables should therefore be a priority to guide conservation policies, as changes in the temporal patterns of LAI and pigment variations could be due to vegetation stress.

Field sampling and laboratory measurements of these traits are not acceptable methods to monitor vegetation, as they are time-consuming, spatially limited, and cannot capture inter- and intraspecies variability. Remote sensing, using either multispectral or hyperspectral sensors, has been extensively used to map LAI and leaf pigments over large swathes [13-16] and allows for recurrent revisits of the study sites. Spectral images are obtained by sensors measuring forest canopy reflectance over a large spectrum, so that slight variations can be detected in the forest canopy's reflected radiation. However, these variations are not exclusively due to the vegetation. Indeed, illumination, local atmospheric conditions, and ground reflectance also have an influence on the measured reflectance [17-19]. Ground reflectance contribution to the measured spectrum can be most problematic for open canopies or sparse forests (which have very low LAI) such as woodland savannas, which are one of the major plant communities in the Mediterranean biome. Indeed, while at high spatial resolutions vegetation pixel could be clearly identified, reducing ground influence, pixels from images with medium to low spatial resolution will only have a limited canopy contribution to the overall reflectance.

Remote sensing pigment and LAI estimation methods can belong to three main families: Empirical-statistical approaches, which fit a model to a set of validation data acquired in-field; physical approaches, which rely on radiative transfer model (RTM) inversions; and hybrid methods, which are still in their infancy and combine the properties of physically-based methods with the flexibility of the empirical-statistical approaches [20]. While empirical-statistical approaches have the disadvantage of difficult transferability to other sensors, sites, or dates, as the model may be overfit, RTM inversions' principal drawback is their ill-posedness: An RTM simulates top-of-canopy reflectance using a modeled scene and physical principles to compute the radiative budget, and various sets of inputs may lead to similar outputs as the problem faces too many unknown variables. However, various options have been successfully explored to mitigate these issues and obtain reliable solutions, such as using prior information to lower the variability of the estimations' distribution or introducing spatial constraints during the inversion process (see an overview of possible options in Baret and Buis [21]). In the present study, a look-up table (LUT)-based RTM inversion was performed using the DART 3D canopy model [22], based on the work done in Adeline et al. [23].

The aim of this study was to find an inversion strategy suited for a heterogeneous tree-grass ecosystem's health (e.g., resiliency to change, continuity in GPP, and nutrient capital [24]) monitoring, i.e., capable of estimating LAI and leaf $\mathrm{C}_{a b}$ and Car over time using multitemporal hyperspectral airborne acquisition with medium ground sampling distance.

Canopy LAI and biochemistry estimations using hyperspectral imagery have mostly been done over canopies with high LAI (for instance, see Banskota et al. [16], le Maire et al. [25], Ali et al. [26], Darvishzadeh et al. [27], Malenovský et al. [28]). While various estimations have also 
specifically been done over open-canopy ecosystems (e.g., the works of Zarco-Tejada et al. [29], Hernández-Clemente et al. [30], Zarco-Tejada et al. [31]), research concerning acceptable modeling methods within RTM is still ongoing [32,33]. The validity of a simplified representation of trees (simple forest representation, SFR) within the DART scene (such as the one done by Gascon et al. [14]) when working with medium-resolution hyperspectral images of very sparse forests was tested in this study, based on the work presented in Widlowski et al. [32]. As acceptable representation of coniferous trees within RTM is still a difficult topic [34]; this study only focused on broadleaved trees as a preliminary test case to study Mediterranean forests. Validation data were available at multiple dates, allowing for a more robust calibration of the inversion method. The validity of the results presented in this paper was assessed using: (i) comparison between estimations and field measurements when and where available, and (ii) comparison between the site's expected and estimated LAI and foliar pigment contents variations over two years.

\section{Materials and Methods}

\subsection{Study Site}

The study site is an oak woodland savanna located in the lower foothills of the Sierra Nevada Mountains (Tonzi Ranch, latitude: $38.431^{\circ} \mathrm{N}$; longitude: $120.966^{\circ} \mathrm{W}$; altitude: $177 \mathrm{~m}$; average slope: $\left.1.5^{\circ}\right)$. The climate is Mediterranean, with wet winters and hot, dry summers without rainfall. The overstory is mainly composed of blue oaks (Quercus Douglasii-QUDO), with a sparse $(<10 \%)$ population of grey pines (Pinus Sabiniana-PISA). Blue oak trees start to become active in April and have shed most of their leaves by November. Spatial distribution and structural composition are typical of heterogeneous canopies, with a mean canopy cover (CC) of $47 \%$ and a mean LAI of $0.8 \mathrm{~m}^{2} / \mathrm{m}^{2}$. The understory is composed of cool season annual C3 grass species: It is active from December to May (wet period) and dry during the summer and autumn. Both oak trees and grasses can therefore be active in April and May. The soil is an Auburn very rocky silt loam (Lithic haploxerepts). More detailed site information can be found in previous studies [35-37]. An aerial picture of the site and its location are given in Figure 1.

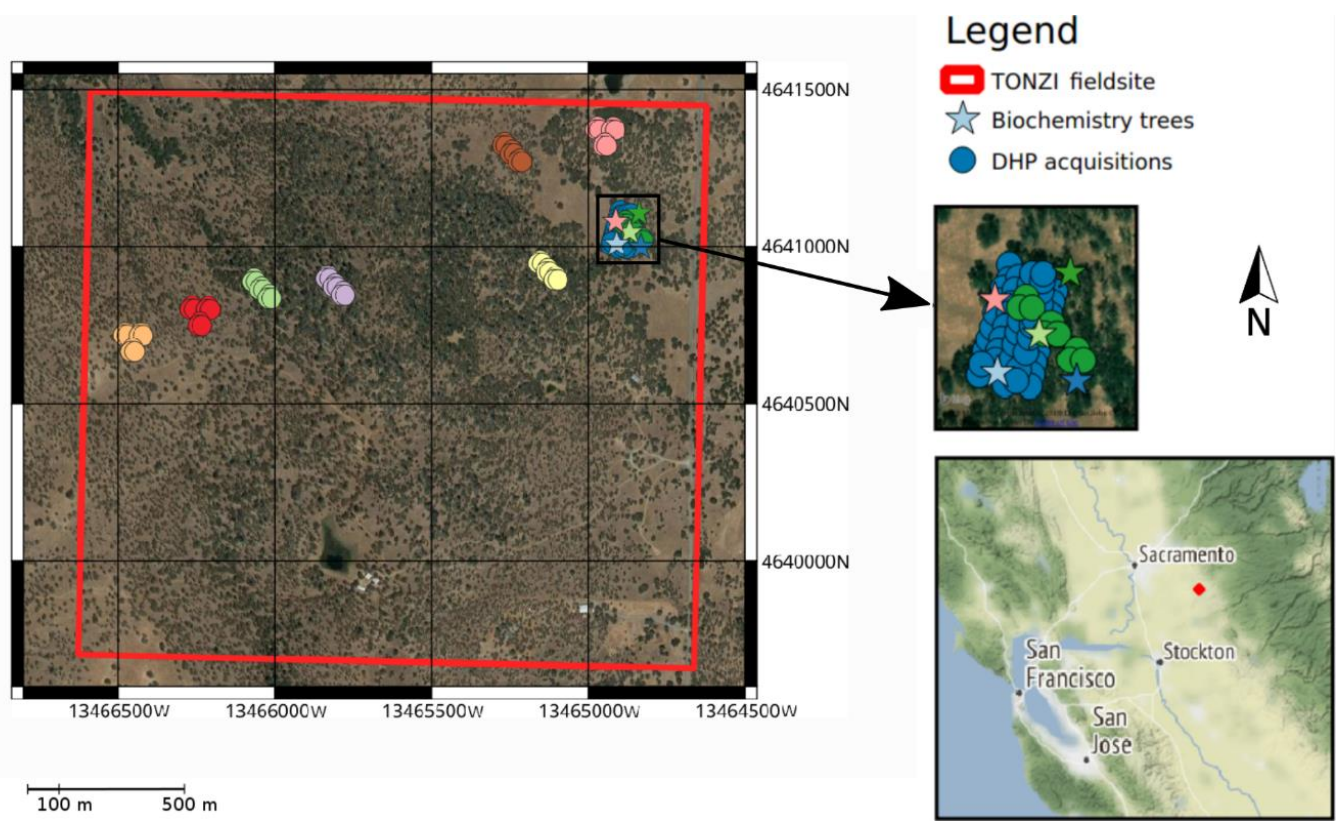

Figure 1. Location of the study site in California (bottom right) and location of field measurements. Discs: Leaf area index (LAI) measured with digital hemispherical photographies (DHP); colors indicate plots differing in species composition and canopy cover. Stars: Trees where leaves were sampled for laboratory biochemistry analysis; colors indicate individual trees. 


\subsection{Field Data}

\subsubsection{Leaf Area Index}

Field data were collected coincident with NASA Hyperspectral Infrared Imager (HyspIRI) Mission Study Airborne Campaigns, which took place in fall 2013 and summers 2014 and 2016 (https: / / hyspiri. jpl.nasa.gov/). Several digital hemispherical photographies (DHP) were collected over multiple $20 \mathrm{~m} \times 20 \mathrm{~m}$ plots across the study site covering all vegetation cover fraction and species composition. The LAI of each plot is therefore considered as an LAI measurement. Information concerning the number of plots for each date is given in Table 1.

From each $20 \mathrm{~m} \times 20 \mathrm{~m}$ plot, three DHP were taken from a Nikon Coolpix 4300 camera post sunset when no direct sunlight is visible. DHP were processed using Hemiview software [38]. Hemiview calculates PAI from the fisheye images estimating image gap fraction using eight azimuth and seven zenith angles. The threshold was estimated for each image based on a visual interpretation. Hemiview calculates an effective plant area index (PAI) that has to be corrected by clumping factors. However, some studies have considered that in forests, effective PAI is almost identical to true LAI, as the underestimation of LAI due to clumping effects could be compensated by the overestimation due to woody structures [39]. In the rest of the paper, effective PAI estimated through Hemiview is therefore considered equal to true LAI and simply referred to as LAI.

\subsubsection{Leaf Biochemistry}

A set of leaves from five QUDO individuals were collected from the upper, sunlit portion of the canopy. Sampling started within an hour of the timing of the overflight. Leaf samples were collected from open grown trees that were in full sunlight, as high into the canopy as possible to reach, and from branches on the east and west side of the tree. Leaves were placed in foil packets so that light would not reach them and stored in a container on blue ice and transferred to a lab refrigerator at the field station until lab measurements could be made, no later than 48 hours after data collection. Leaf samples were frozen in liquid nitrogen for a short time until lyophilized.

The analysis extraction was done in $90 \%$ acetone $(14 \mathrm{~mL})$ for 48 hours, which provided enough solvent extract to make $3.5 \mathrm{~mL}$ samples for each individual. Lambda $25 \mathrm{UV} /$ Vis spectrophotometer runs were done with standards with a concentration of $23 \mathrm{mg} / \mathrm{mL}$ for chlorophylls and $8 \mathrm{mg} / \mathrm{mL}$ for carotenoids. Absorbance $A$ of the solution was measured at 0.470,0.662, 0.645, and $0.710 \mu \mathrm{m}$. Chlorophylls and carotenoids concentrations of the solution $\left(c_{a}, c_{b}, c_{(x+c)}\right)$ were computed using Equations (1)-(3) $[40,41]$ with a dilution factor equal to 3.5, and further processed to get chlorophylls $a+b$ and carotenoid concentration on the leaf area $\left(\mu \mathrm{m} / \mathrm{cm}^{2}\right)$. Information concerning the final number of validation points is given in Table 1.

$$
\begin{aligned}
& c_{a}(\mu \mathrm{g} / \mathrm{mL})=\left(11.24\left(A_{0.662}-A_{0.710}\right)-2.04\left(A_{0.645}-A_{0.710}\right)\right) \times \text { dilution factor } \\
& c_{b}(\mu \mathrm{g} / \mathrm{mL})=\left(20.13\left(A_{0.645}-A_{0.710}\right)-4.19\left(A_{0.662}-A_{0.710}\right)\right) \times \text { dilution factor } \\
& c_{(x+c)}(\mu \mathrm{g} / \mathrm{mL})=\left(\frac{1000\left(A_{0.470}-A_{0.710}\right)-1.90 c_{a}-63.140 c_{b}}{214}\right) \times \text { dilution factor }
\end{aligned}
$$

While leaves from fives trees were originally collected for summer 2013, biochemistry results from two trees were rejected as they showed lower $\mathrm{C}_{\mathrm{ab}}$ and Car values than those from the same trees in fall 2013 ( 20 to $37 \mu \mathrm{g} / \mathrm{cm}^{2}$ and 34 to $38 \mu \mathrm{g} / \mathrm{cm}^{2}$ from summer to fall, respectively). This is contrary to the expected behavior of these pigments, and it was assumed that the leaf samples from those trees suffered degradation between collection and laboratory analysis.

\subsubsection{Trunk Reflectances}

Trunk reflectances of QUDO trees were collected using an Analytical Spectral Devices, ASD Inc., Boulder, CO, USA contact probe. The spectroradiometer was calibrated using a spectralon panel as a 
white reference before every acquisition. Trunk reflectances were obtained over the $0.350-2.500 \mu \mathrm{m}$ spectral range.

Table 1. The number of validation points for LAI and leaf biochemistry and associated dates of collection. See Table 2 for more detailed information concerning the date of collection.

\begin{tabular}{ccc}
\hline & \multicolumn{2}{c}{ Validation Data } \\
Date & LAI & Biochemistry \\
\hline Summer 2013 & & 3 \\
Fall 2013 & 12 & 5 \\
Summer 2014 & 19 & 5 \\
Summer 2016 & 21 & \\
\hline Total & 52 & 13 \\
\hline
\end{tabular}

\subsubsection{Airborne Hyperspectral Remote Sensing Data}

AVIRIS-C hyperspectral data are processed and delivered by NASA Jet Propulsion Laboratory (JPL; http:/ / aviris.jpl.nasa.gov). The sensor is a whiskbroom scanner with an instantaneous field of view of $1 \mathrm{mrad}$ and a total field of view of $34^{\circ}$. It is composed of 224 contiguous bands with a full width at half maximum (FWHM) of $0.010 \mu \mathrm{m}$ from 0.365 to $2.5 \mu \mathrm{m}$ [42]. Airborne acquisitions took place in spring, summer, and fall (corresponding to the 3 phenological stages) from 2013 to 2015 and every summer from 2016 to 2018. Images were acquired at nadir. Acquisitions used in this study are given in Table 2. The ER-2 aircraft flew $20 \mathrm{~km}$ above the ground, around noon, in order to avoid spectral directional effects. Preprocessing steps provided by NASA JPL included radiometric calibration, geometrical orthorectification, nearest neighbor spatial resampling at $18 \mathrm{~m}$, and atmospherical correction performed with ATREM [43], in order to retrieve surface reflectance. Additional flights over the study site were done during the summer 2014 using the AVIRIS-Next Generation (AVIRIS-NG) sensor. AVIRIS-NG images have a $2 \mathrm{~m}$ spatial resolution and 432 spectral bands with a FWHM of $0.005 \mu \mathrm{m}$ from 0.380 to $2.510 \mu \mathrm{m}$.

Table 2. Description of AVIRIS-C and AVIRIS-NG airborne acquisitions.

\begin{tabular}{lccccc}
\hline & & \multicolumn{2}{c}{ AVIRIS-C } & \multicolumn{2}{c}{ AVIRIS-NG } \\
Year & Season & Date (DOY ${ }^{\text {1) }}$ & Time (PDT ${ }^{2}$ ) & Date (DOY) & Time (PDT) \\
\hline \multirow{2}{*}{2013} & Spring & 2 May (122) & 01h30 p.m. & & \\
& Summer & 4 June (155) & 12h30 p.m. & & \\
2014 & Fall & 19 September (262) & 12h40 p.m. & & \\
& Summer & 2 June (153) & 12h00 p.m. & 6 June (157) & 12h24 p.m. \\
& Spring & 29 April (119) & 11h40 a.m. & & \\
2015 & Summer & 8 June (159) & 01h40 p.m. & & \\
& Fall & 13 October (286) & 12h30 p.m. & \\
2016 & Summer & 9 June (161) & 12h30 p.m. & \\
2018 & Summer & 20 June (171) & 01h00 p.m. & \\
\hline
\end{tabular}

${ }^{1}$ Day of Year; ${ }^{2}$ Pacific Daylight Time.

\subsection{General Methodology}

In the present section, a description of each step of the methodology followed in this study is given. Figure 2 presents an outline of the steps described in the following subsections.

\subsubsection{Image Processing for Multitemporal AVIRIS-C Data}

In addition to the image processing protocol from NASA JPL, co-registration was further considered to improve the spatial matching between the AVIRIS-C images over the Tonzi site. The reference image was the summer 2014 AVIRIS-NG image, as the georeferencement seemed 
acceptable when overlaid on QGIS Microsoft Bing Maps satellite backgrounds. Co-registration was based on a nearest-neighbour resampling using around 25 ground control points per image. This amount could vary depending whether or not some features were identifiable on the AVIRIS-C images. For each image, the co-registration root mean square error (RMSE) was less than one pixel.

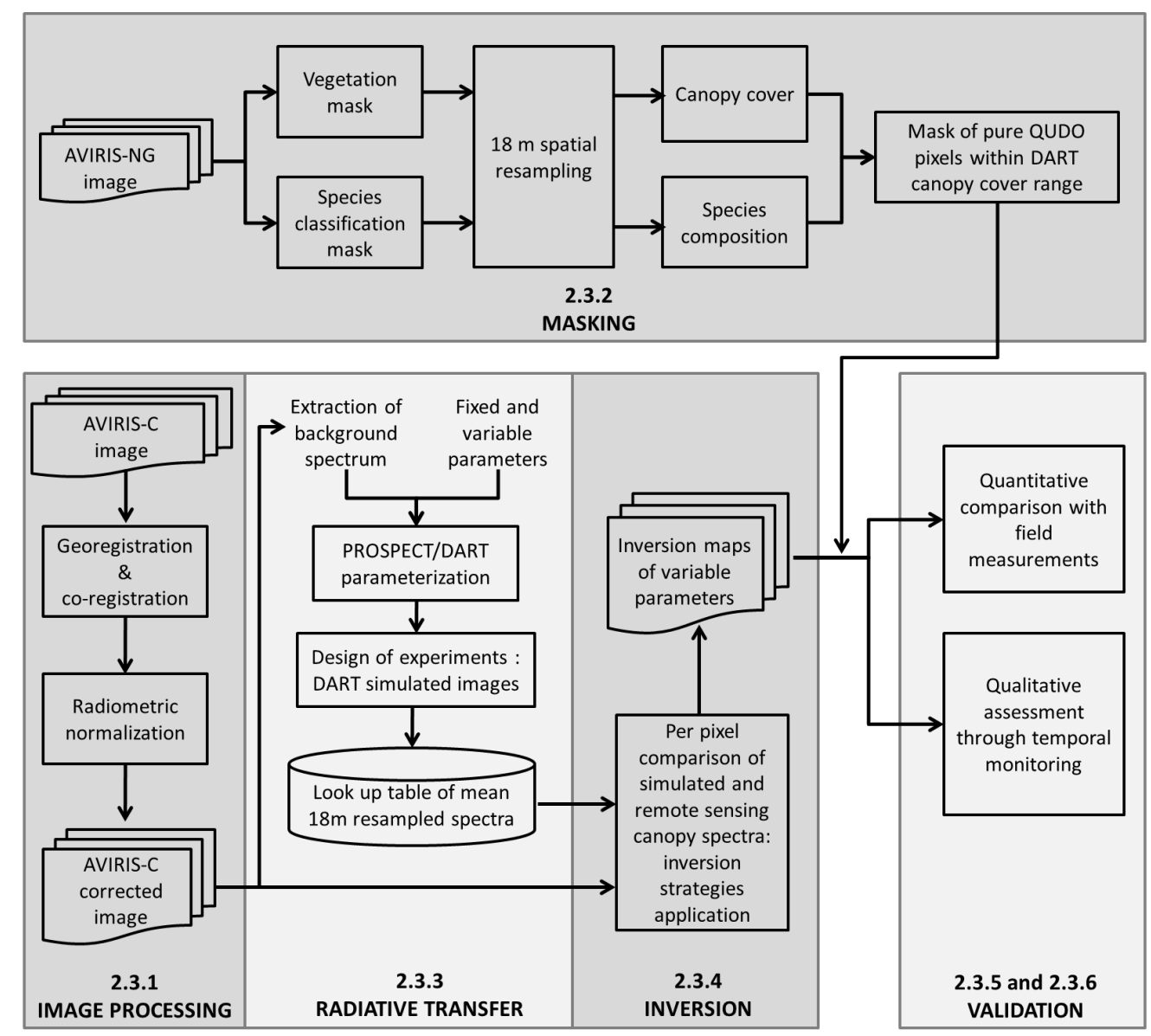

Figure 2. Methodology followed in the present study.

A temporal correction was also applied on the images, serving as an in-between flight radiometric normalization in order to compare the images on the same spectral baseline. An empirical line correction method [44-46] was done using 9 invariant targets (3 black targets from the waters of Tahoe lake; 3 grey targets from flat sand/gravel areas; 3 white from different flat roofs with white painting) within the AVIRIS-C atmospherically corrected reflectance images. The reference image for the temporal correction was the spring 2013 AVIRIS-C image. The calibration targets were all located outside of the Tonzi site and spectral comparison over the various AVIRIS-C images showed that they were invariant in time.

\subsubsection{Masking Using Canopy Cover and Species Composition Maps Derived From the AVIRIS-NG Image}

The objective was to create a monospecific mask of QUDO. The final monospecific mask was obtained by (i) eliminating the areas with too many PISA in the images, (ii) eliminating pixels with too low tree presence $(C C<10 \%)$ and (iii) removing the pixels containing water, roads, and manmade infrastructures. The AVIRIS-NG image at $2 \mathrm{~m}$ spatial resolution was processed to derive a $18 \mathrm{~m} \mathrm{CC}$ map as well as a species composition map. Figure 3 gives an overview of the processing steps done over the AVIRIS-NG image. 
To build a canopy cover map, a vegetation mask was built based on a simple histogram thresholding with the application of a vegetation index. Version 2 of the modified chlorophyll absorption ratio index (MCARI2, [47]) was chosen given that the two main components in the image can be easily separated in summer: A healthy green tree canopy (chlorophylls peak) and dry dead grass (no chlorophyll). Finally, a spatial resampling was applied using the pixel aggregate method to come back to the $18 \mathrm{~m}$ spatial resolution of AVIRIS. The statistics provided from the derived canopy cover map show that the mean canopy cover is 53\% over the area of interest with a concave bell curve from $0 \%$ to $90 \%$. In addition, a peak also appears around $100 \%$ in the distribution histogram (see Figure 3).

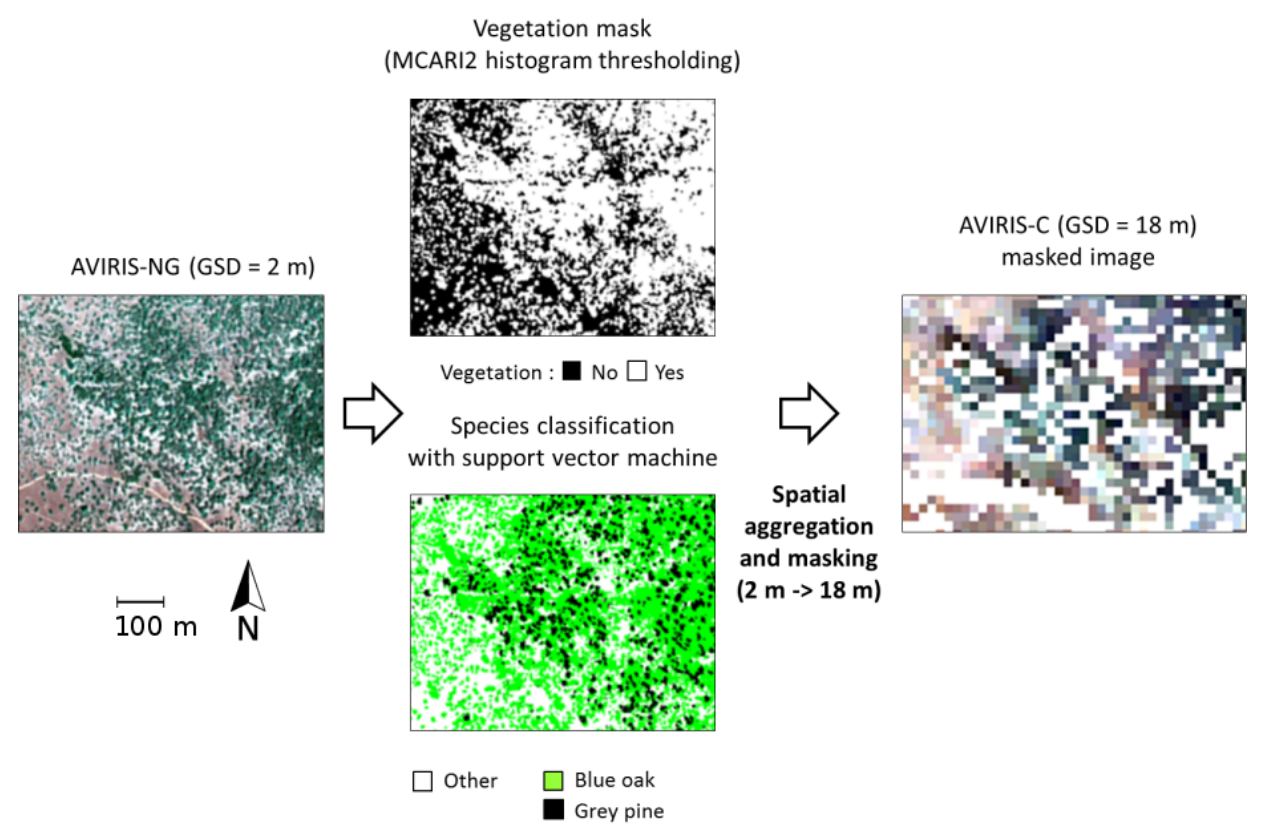

Figure 3. Steps used for the mask building using the AVIRIS-NG image and masking of the AVIRIS-C images.

To build the species classification map, the supervised support vector machine (SVM) classification method was used through the program LibSVM [48]. One class was created for each tree species (QUDO and PISA). A total of 506 and 557 pixels were respectively selected for each class as training samples based on fieldwork data, tree structural information derived from LiDAR data collected in 2009 (PISA sample height assumed to be higher than $20 \mathrm{~m}$, [49]) and visual inspection. A total of 339 spectral bands were selected to obtain the same spectral bands as AVIRIS-C. The SVM was run with the radial basis function kernel (C: 6.5; $\gamma: 0.0055$; accuracy: 93\%; cross-validation correlation coefficient: 98.4). For verification purposes, the resulting classification map was also visually compared to a true-color image of the site, as the tree species have clearly distinct colors. Finally, an $18 \mathrm{~m}$ species composition map was created by applying the same spatial resampling as for the canopy cover map.

Pixels where QUDO crowns represented less than $80 \%$ of the total tree crowns were rejected as the PISA presence would be too high, as well as pixels with a CC below $10 \%$. Finally, pixels containing water, roads, and manmade infrastructures were manually masked over each image.

\subsubsection{DART and PROSPECT Radiative Transfer Models Parametrization}

DART version 5.7.3v1078 was used to simulate canopy reflectances and build the LUT. DART is a radiative transfer model able to simulate light interactions and multiple scattering effects within the modeling of a 3D scene, including the topography and the atmosphere. The 3D scene is a made of voxels whose size can be set by the user to simulate various scene elements. These elements can be represented through planar elements (triangles, allowing for precise modeling) and/or turbid 
voxels (statistical representation of fluids and vegetation). In the case of vegetation, these turbid voxels properties are determined by the canopy leaf area and its spatial distribution, the leaf angle distribution (LAD), and leaf optical properties. A more precise description of the DART model can be found in Gastellu-Etchegorry et al. [22] and Gastellu-Etchegorry et al. [50]. DART makes it possible to define trees with simplified representations such as turbid crowns of conic, spherical, or ellipsoidal shape and allows for tuning of the fraction on full voxels within the crown as well as branches and twigs modeling. Therefore, trees are defined by structural parameters such as the shape and size of their crown and the distribution of their branches and leaf cells, as well as optical parameters with the optical properties of leaf voxels and branches.

The scene modeling done in this study is based on a simplified forest representation. A repetitive pattern of four trees with ellipsoidal crowns was used [14]. Crown size and height were set to the Tonzi site average values [36]. Branches and twigs were neglected to reduce modeling complexity and introduction of errors if not correctly set. Trunk reflectance was set to the value measured in-field. Canopy cover variations were obtained by increasing the scene dimensions. The trees were placed so that the scene bidirectional reflectance factor (BRF) is the closest to a forest BRF, following the pattern given in Gastellu-Etchegorry et al. [51] and Gascon et al. [14]. Trees and scene characteristics are given in Table 3. The forest understory was represented as a lambertian surface whose optical properties were determined by pure soil pixels selected within the AVIRIS-C images in open parts of the site, at least one pixel $(18 \mathrm{~m})$ away from canopy pixels and several pixels wide. These open parts were visually chosen using QGIS high-resolution Microsoft Bing Maps satellite backgrounds. Leaf optical properties were simulated through the PROSPECT model [52] implemented in DART, using the input parameters described in Table 4. The leaf structure parameter $\mathrm{N}$ was set to 1.8. Sun and atmosphere were the only radiation sources. The sun positions were set so that they match with the AVIRIS-C images based on site location and hours of acquisition. The simulations used a rural aerosol model with a visibility of $23 \mathrm{~km}$ corresponding to mid-latitude summer standard atmosphere. A total of 168 bands with a spectral bandwidth of $0.010 \mu \mathrm{m}$ were simulated between 0.36 and $2.45 \mu \mathrm{m}$ to cover both the visible and short wave infrared (SWIR) spectral ranges.

Table 3. DART elementary scene fixed and variable input parameters used for the LUT generation.

\begin{tabular}{lccc}
\hline \multicolumn{1}{c}{ Parameters } & Values/Range & Step & Number of Values \\
\hline General settings & & & \\
\hline CC $(\%)$ & $10-90$ & 20 & 5 \\
Scene dimensions $x \times y\left(\mathrm{~m}^{2}\right)$ for: & & & \\
CC $10 \%$ & $32.4 \times 32.4$ & & \\
CC 30\% & $18.8 \times 18.8$ & & \\
CC $50 \%$ & $14.4 \times 14.4$ & \\
CC 70\% & $12.4 \times 12.4$ & \\
CC 90\% & $10.8 \times 10.8$ & \\
Voxel size $x, y, z(\mathrm{~m})$ & $0.4,0.4,0.4$ & \\
\hline Tree characteristics & & \\
\hline Tree height $(\mathrm{m})$ & 9.4 & \\
Crown shape & ellipsoidal & \\
Crown diameter $(\mathrm{m})$ & 5.8 & \\
Crown height $(\mathrm{m})$ & 7.5 & \\
Trunk height $($ below \& within crown) $(\mathrm{m})$ & $1.9,4.73$ & \\
Trunk dbh $(\mathrm{m})$ & 0.26 & \\
\hline
\end{tabular}


Table 4. Leaf fixed and variable input parameters used for the LUT generation.

\begin{tabular}{lcccc}
\hline \multicolumn{1}{c}{ Parameters } & Acronym & Values/Range & Step & Number of Values \\
\hline Leaf Angle Distribution & LAD & spherical & & \\
Leaf Area Index $\left(\mathrm{m}^{2} / \mathrm{m}^{2}\right)$ & LAI & $0.1-1.9$ & 0.3 & 7 \\
Chlorophylls a $+\mathrm{b}$ content $\left(\mu \mathrm{g} / \mathrm{cm}^{2}\right)$ & $\mathrm{C}_{a b}$ & $10-60$ & 10 & 6 \\
Carotenoid content $\left(\mu \mathrm{g} / \mathrm{cm}^{2}\right)$ & $\mathrm{Car}_{2}$ & $2-22$ & 4 & 6 \\
Dry matter content $\left(\mathrm{g} / \mathrm{cm}^{2}\right)$ & $\mathrm{C}_{m}$ & $0.001-0.016$ & 0.003 & 6 \\
Equivalent Water Thickness $(\mathrm{cm})$ & $\mathrm{C}_{w}$ & $0.001-0.021$ & 0.004 & 6 \\
\hline
\end{tabular}

\subsubsection{Inversion Stategies}

This study follows a LUT-based approach consisting in finding the DART model parameters minimizing a cost function comparing measured $y$ to computed $\hat{y}$ reflectances. Since the inversion problem is ill-posed, multiple sets of parameters can yield similar reflectances. A common estimation method is to consider the mean values from the $q$ best sets of parameters as the final solution [53,54]. Various cost functions were tested: Root mean square error (RMSE, Equation (4)), spectral angle (SAM, Equation (5)) and vegetation index (VI) differences ( $D_{V I}$, Equation (6)).

$$
\begin{gathered}
\operatorname{RMSE}(y, \hat{y})=\sqrt{\frac{1}{N} \sum_{i=1}^{N}\left(y_{i}-\hat{y}_{i}\right)^{2}} \\
\operatorname{SAM}(y, \hat{y})=\cos ^{-1}\left(\frac{\sum_{i=0}^{N} y_{i} \hat{y}_{i}}{\sqrt{\sum_{i=1}^{N} \hat{y}_{i} \hat{y}_{i}} \sqrt{\sum_{i=1}^{N} y_{i} y_{i}}}\right) \\
D_{V I}(y, \hat{y})=a b s(V I(y)-V I(\hat{y}))
\end{gathered}
$$

RMSE and SAM were computed using variable-specific spectral intervals. The near infrared (NIR) and SWIR were used for LAI (INT LAI, $0.8-2.45 \mu \mathrm{m}$ ), while parts of the visible range were used for $\mathrm{C}_{a b}$ and Car (INT CAB, 0.5-0.75 and INT CAR, $0.5-0.55 \mu \mathrm{m}$ respectively). $D_{V I}$ was computed using various indices. Concerning LAI, the NDVI was selected, as it is commonly used to estimate vegetation cover, as well as MSAVI2, which is a soil-adjusted index; for $C_{a b}$, Maccioni, GM_94b, gNDVI, MCARI2, and TCARI/OSAVI were considered, since they are soil-adjusted indices specifically designed for low-LAI environments, and they were successfully used in a sparse forest context [47,55-57]; concerning Car, CRI and R515/R570 were chosen, as they were also successfully used in previous studies [30,57]. Table 5 summarizes the selected methods for all investigated variables as well as the number of spectral bands used.

The number $q$ of best-matching cases to use for the inversion was selected on a per-variable basis. The objective was to find an optimal value that would minimize the RMSE between field data and estimations when performing the LUT-based inversion. Therefore, inversions were done with increasing $q$ values, from 1 to 400 (0.9\% of the LUT). If an optimal value existed across all validation dates, it would determine the number of solutions to keep for the inversion validation step (Section 2.3.5) and then the inversion of all remaining AVIRIS-C dates available.

\subsubsection{Validation Metrics}

Validation was performed by comparing LAI, chlorophylls, and carotenoids estimates with the field measurements available using RMSE, bias, the $R^{2}$ of the predicted-vs.-measured regression line and the STDB (standard deviation of the difference between estimated points and the regression line) as cost functions.

Concerning LAI, each validation point was the average of LAI values derived from 3 hemispherical pictures taken within a $20 \times 20 \mathrm{~m}$ plot (see Section 2.2.1). Therefore, one LAI validation point does not necessarily only contain information about the LAI of the AVIRIS-C pixel it is associated with. Figure 4 
illustrates the issue: Since the AVIRIS pixels and the grid used for DHP acquisitions have no reason to match, some DHP (dots) may have been acquired out of the pixel the final LAI has been associated with (red square). Direct comparison between pixel-estimated value and validation data can therefore be inappropriate, especially for spatially heterogeneous canopies. To address this, LAI validation points were compared to a spatially smoothed LAI inversion map. The spatial smoothing was done by computing the average LAI within a sliding window with an aperture size of 3 pixels. The aperture size was set to 3 as the LAI validation plot size $(20 \times 20 \mathrm{~m})$ roughly matches the AVIRIS-C pixel size $(18 \times 18 \mathrm{~m})($ Figure 4$)$.

Table 5. Spectral strategies applied for the inverse problem.

\begin{tabular}{|c|c|c|c|c|}
\hline Parameter & Method & $\mathbf{N}_{\text {bands }}$ & VI Formula (Wavelengths in $\mu \mathrm{m}$ ) & Reference \\
\hline \multirow{5}{*}{ LAI } & RMSE INT LAI & 120 & & \multirow{4}{*}{ [58] } \\
\hline & SAM INT LAI & 120 & & \\
\hline & \multirow{2}{*}{$D_{N D V I}$} & \multirow{2}{*}{2} & \multirow{3}{*}{$\frac{\frac{\rho_{0.833}-\rho_{0.677}}{\rho_{0.833}+\rho_{0.677}}}{\frac{1}{2}\left(2 \rho_{0.800}+1-\sqrt{\left.\left(2 \rho_{0.800}+1\right)^{2}-8\left(\rho_{0.800}-\rho_{0.670}\right)\right)}\right.}$} & \\
\hline & & & & \\
\hline & $D_{M S A V I 2}$ & 2 & & [55] \\
\hline \multirow{11}{*}{$\mathrm{Cab}$} & RMSE INT CAB & 27 & \multirow{4}{*}{$3 \frac{\left(\rho_{0.700}-\rho_{0.670}\right)-0.2\left(\rho_{0.700}-\rho_{0.550}\right) \frac{\rho_{0.700}}{\rho_{0.670}}}{1.16 \frac{\rho_{0.800}-\rho_{0.670}}{\rho_{0.800}+\rho_{0.670}+0.16}}$} & \multirow{4}{*}{ [59] } \\
\hline & SAM INT CAB & 27 & & \\
\hline & $D_{\text {талын }}$ & 4 & & \\
\hline & \multirow{3}{*}{$D_{M A C C I O N I}$} & \multirow{3}{*}{3} & & \\
\hline & & & $\underline{\rho_{0.780}-\rho_{0.710}}$ & \multirow{2}{*}[60]{} \\
\hline & & & $\rho_{0.780}-\rho_{0.680}$ & \\
\hline & \multirow{2}{*}{$D_{g N D V I}$} & 2 & $\underline{\rho_{0.780}-\rho_{0.550}}$ & \multirow{2}{*}[61]{} \\
\hline & & \multirow{2}{*}{2} & $\begin{array}{c}\rho_{0.780}+\rho_{0.550} \\
\underline{\rho_{0.750}}\end{array}$ & \\
\hline & $D_{G M \_94 b}$ & & $\overline{\rho_{0.550}}$ & [62] \\
\hline & \multirow{2}{*}{$D_{M C A R I 2}$} & \multirow[t]{2}{*}{3} & $1.5 \frac{\left.2.5\left(\rho_{0.800}-\rho_{0.670}\right)-1.3\left(\rho_{0.800}-\rho_{0.550}\right)\right)}{}$ & \multirow{2}{*}{ [47] } \\
\hline & & & $\sqrt{\left(2 \rho_{0.800}+1\right)^{2}-\left(6 \rho_{0.800}-5 \sqrt{\rho_{0.670}}\right)-0.5}$ & \\
\hline \multirow{5}{*}{ Car } & RMSE INT CAR & 6 & & \multirow{4}{*}[30]{} \\
\hline & SAM INT CAR & 6 & & \\
\hline & $D_{R 515 / R 570}$ & 2 & $\underline{\rho_{0.515}}$ & \\
\hline & \multirow[b]{2}{*}{$D_{C R I}$} & & $1^{\rho_{0.550}}{ }_{1}$ & \\
\hline & & 2 & $\overline{\rho_{0.515}}-\overline{\rho_{0.570}}$ & [63] \\
\hline
\end{tabular}

Biochemistry validation data were obtained at the leaf scale, for a single tree in each validation pixel. There is therefore an unavoidable uncertainty, as validation is done by comparing field data at the leaf scale (single tree) to plot biochemistry (canopy scale, multiple trees). An assumption is made that tree biochemistry does not vary much spatially, and $\mathrm{C}_{a b}$ and Car estimations were directly extracted from the pixels associated to the acquisition positions. 


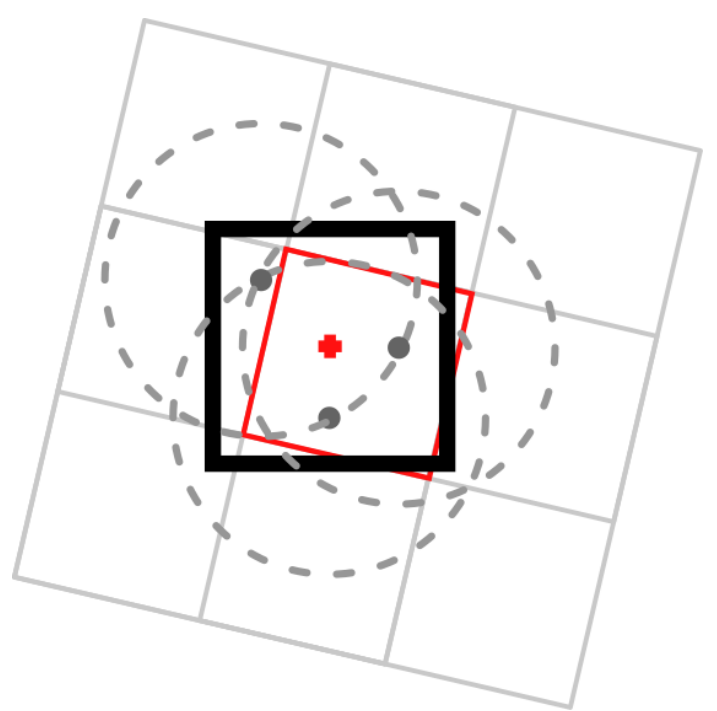

Figure 4. Diagram showing one LAI validation point (red dot) within its $20 \times 20 \mathrm{~m}$ plot (bold square). The validation point falls within the AVIRIS-C pixel in red. Other pixels are represented by the grey grid. LAI is derived from 3 digital hemispherical photographies (DHP) taken at various locations within the plot, each one covering an area approximated by a dashed circle.

\subsubsection{Seasonal Monitoring}

To provide a qualitative validation of LAI and pigment estimations, estimations using the best inversion strategies (Sections 3.3.2 and 3.3.3) were computed, and seasonal variations were monitored and compared to expected variations. The seasonal monitoring involved LAI and foliar $\mathrm{C}_{a b}$ and Car. Estimation maps were built using AVIRIS-C acquisitions done in the spring (DOY 122 and 119), summer (DOY 155 and 159), and fall (DOY 262 and 286) of 2013 and 2015. Each estimation's uncertainty is the STDB of the variables' estimations (STDB are presented in Sections 3.3.2 and 3.3.3). Changes in the site's mean LAI and foliar $C_{a b}$ and Car were considered significant if they were greater than the STDB of their respective variables.

\section{Results}

\subsection{Comparison between Airborne and DART-Simulated Reflectances}

The assessment of LUT reflectances acceptability with regard to those measured by AVIRIS-C was done in two steps. First, DART-simulated reflectances of each LUT were plotted and compared to the reflectances measured by AVIRIS-C at the associated date (see, for example, Figure 5). All LUTs consistently overestimated canopy reflectances between 0.75 and $1.1 \mu \mathrm{m}$, with the mean image reflectance being either barely within or below LUT reflectances near the red-edge. Image reflectances in the visible and SWIR regions were, however, within simulation ranges. 


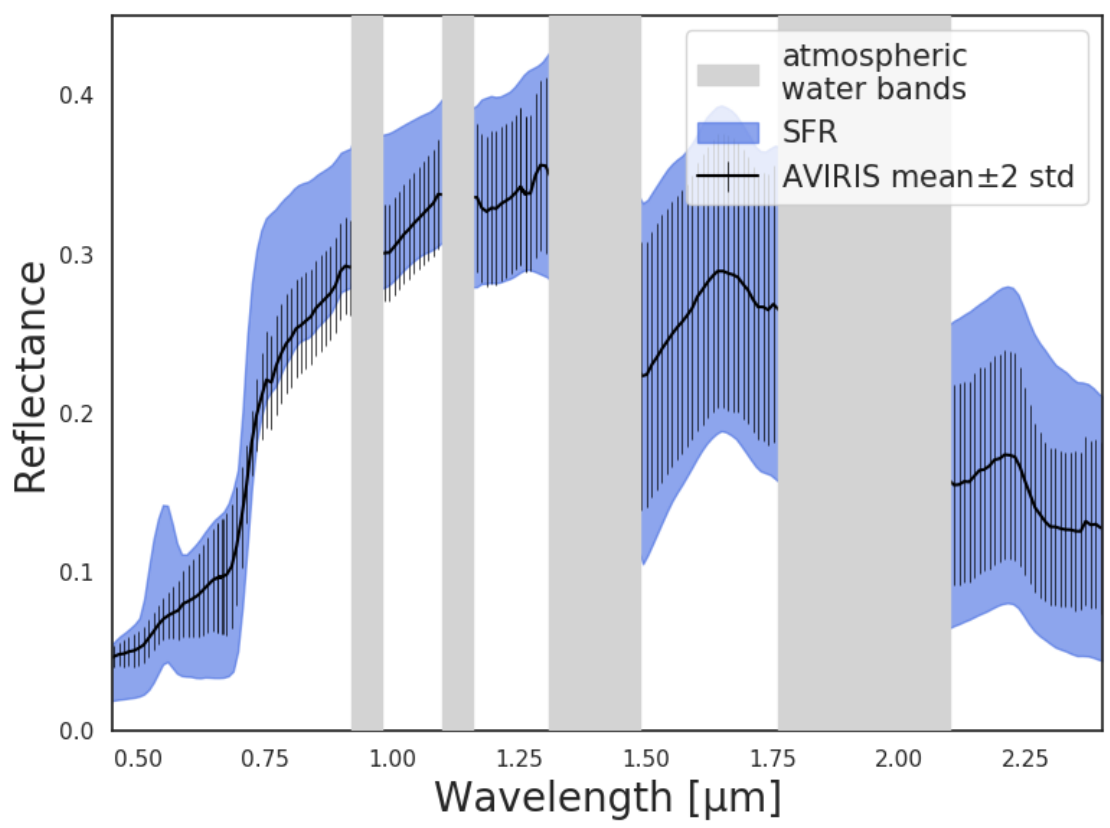

Figure 5. Reflectances computed by the DART simulations compared to reflectances of vegetation pixels within the AVIRIS-C image for summer 2014.

Secondly, the amount of pixels that could be explained by the LUTs was evaluated. The percentages of pixels explained by the LUTs within each image are given in Table 6. LUT reflectances encompass image reflectances at various degrees depending on the spectral intervals considered (INT LAI, INT CAB, INT CAR). On average, $54 \%$ of pixels' reflectances completely fall within the LUT reflectance boundaries for INT LAI. This goes up to $67 \%$ and $97 \%$ for INT CAB and INT CAR, respectively. When considering the vegetation indices computed from both images and LUT reflectances, pixel-derived vegetation index (VI) are within LUT-derived VI boundaries from $90 \%$ to $100 \%$ of the time (excepting summer 2017 , which has one occurrence at $83 \%$ ), depending on the VI considered.

Table 6. Percentages of pixels within AVIRIS-C images which reflectance (for INT LAI, INT CAB, and INT CAR rows) or associated vegetation indices (other rows) are within those derived from the DART LUT.

\begin{tabular}{|c|c|c|c|c|c|c|c|c|c|c|c|}
\hline & & Spr. & $\begin{array}{l}2013 \\
\text { Sum. }\end{array}$ & Fall & $\begin{array}{l}2014 \\
\text { Sum. }\end{array}$ & Spr. & $\begin{array}{l}2015 \\
\text { Sum. }\end{array}$ & Fall & $\begin{array}{l}2016 \\
\text { Sum. }\end{array}$ & $\begin{array}{l}2017 \\
\text { Sum. }\end{array}$ & $\begin{array}{l}2018 \\
\text { Sum. }\end{array}$ \\
\hline \multirow{3}{*}{ LAI } & INT LAI & 32 & 58 & 67 & 62 & 67 & 65 & 53 & 25 & 56 & 55 \\
\hline & NDVI & 99 & 99 & 99 & 100 & 99 & 98 & 97 & 99 & 99 & 97 \\
\hline & MSAVI2 & 96 & 98 & 94 & 99 & 93 & 97 & 90 & 97 & 98 & 96 \\
\hline \multirow{6}{*}{$\mathrm{C}_{a b}$} & INT CAB & 46 & 71 & 84 & 82 & 84 & 79 & 71 & 33 & 60 & 62 \\
\hline & MCARI2 & 98 & 98 & 91 & 99 & 97 & 98 & 90 & 98 & 98 & 97 \\
\hline & TCARI/OSAVI & 100 & 100 & 97 & 99 & 100 & 98 & 98 & 93 & 98 & 97 \\
\hline & Maccioni & 100 & 100 & 100 & 100 & 100 & 100 & 100 & 100 & 100 & 100 \\
\hline & gNDVI & 100 & 100 & 100 & 100 & 100 & 100 & 100 & 100 & 100 & 100 \\
\hline & GM_94b & 100 & 100 & 100 & 100 & 100 & 100 & 100 & 100 & 100 & 100 \\
\hline \multirow{3}{*}{ Car } & INT CAR & 100 & 100 & 100 & 100 & 100 & 99 & 100 & 100 & 94 & 78 \\
\hline & R515/R570 & 100 & 100 & 100 & 100 & 100 & 100 & 100 & 100 & 100 & 100 \\
\hline & CRI & 100 & 99 & 100 & 100 & 100 & 92 & 100 & 93 & 83 & 68 \\
\hline
\end{tabular}




\subsection{Influence of the Canopy Cover on Vegetation Indices}

Once the LUT was built, it was also necessary to assess the suitability of each VI to serve as a criterion for LAI and biochemistry estimations when using the LUT entries. Indeed, it is clear that the green vegetation signal is quite low. The reflectance of low CC pixels is close to that of pure ground, with only a slight red-edge increase (Figure 6). Even at high CC, the red-edge is not very steep, and the chlorophylls reflectance peak at $0.55 \mu \mathrm{m}$ is barely visible: It could be possible that some VIs would not be able to detect some of the variations of the variables of interest.

To do this assessment, vegetation indices were computed over the LUT reflectances. Figure 7 shows the evolution of three different VIs over the variable they are associated with, on a per-CC basis (colors). Ideally, no matter the CC, the VI should present variations when their associated variable increases, i.e., behave as a bijective function.

It was found that the indices selected for LAI estimations all started saturating at $0.4 \mathrm{~m}^{2} / \mathrm{m}^{2} \mathrm{LAI}$ for the $10 \%$ of CC cases (Figure $7 \mathrm{a}$, red line). This behavior was not found for higher CC. Since the $10 \%$ $\mathrm{CC}$ category could only bring confusion due to this saturation when estimating LAI, it was decided to remove these cases from the LUT. Excluding these cases could also be done based on their lack of realism, as low CC-high LAI canopies are unrealistic. Vegetation indices dedicated to $\mathrm{C}_{a b}$ and $\mathrm{Car}$ estimation did not show such behavior (Figure $7 \mathrm{~b}, \mathrm{c}$ ); therefore, all CC cases were considered during the inversion step for $C_{a b}$ and Car.

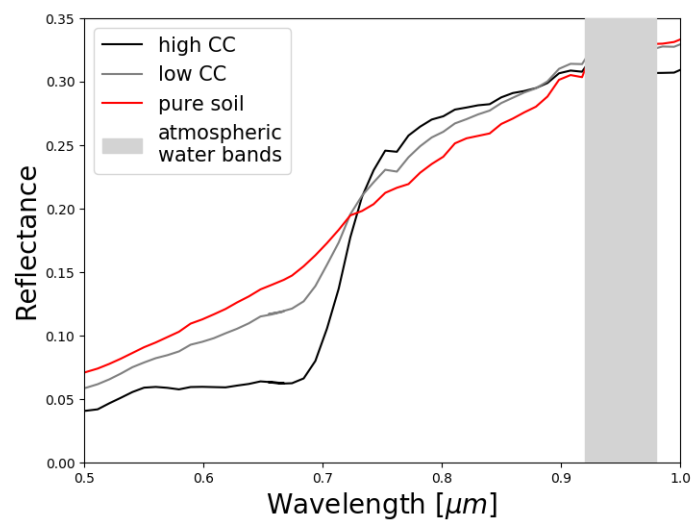

Figure 6. Reflectances of a low (grey) and a high (black) canopy cover Quercus Douglasii (QUDO) pixel in summer 2014. In red, reflectance of a pure ground pixel. 


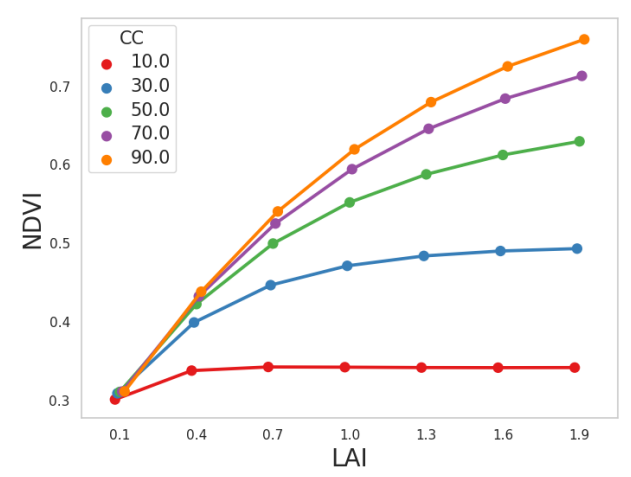

(a) NDVI

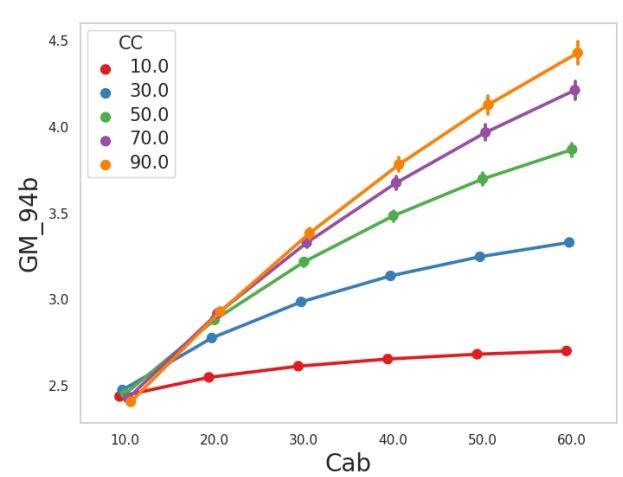

(b) GM_94b

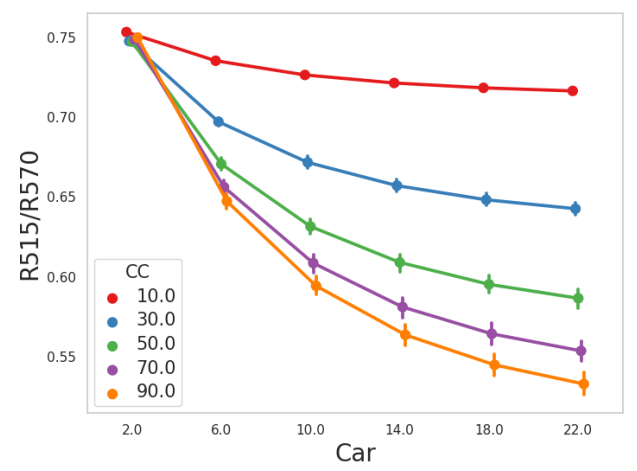

(c) R515/R570

Figure 7. Computed Vegetation Index (VI) for each LUT entry over (a) LAI, (b) $\mathrm{C}_{a b}$, and (c) Car. In color, distinction by CC. Only one example is given for each variable, as other VIs behaved the same.

\subsection{Selection of the Best Inversion Strategy}

\subsubsection{Determination of the Number $q$ Achieving the Best Inversion Performances}

For each variable, in order to assess the uncertainty associated with determining $q$ using only validation data from a single date, $q$ was determined both on a date-to-date basis and on a multidate basis.

For LAI, ignoring the RMSE INT criterion which performed very poorly, all criteria seemed to have reached a plateau by $q=100$ at most (see Table 7 and Figure 8a). As there was no obvious optimal $q$ which could minimize RMSE, it was decided to consider the 100 best performing solutions for LAI estimation. While for summers 2014 and 2016, SAM INT LAI, NDVI, and MSAVI2 performed similarly, for fall 2013, only the VI-based criteria achieved acceptable performances (around $0.6 \mathrm{~m}^{2} / \mathrm{m}^{2}$ for RMSE and SAM INT LAI, around $0.2 \mathrm{~m}^{2} / \mathrm{m}^{2}$ for NDVI and MSAVI2).

$C_{a b}$ results showed a similar plateauing behavior (see Table 7 and Figure $8 b$ ). Therefore, it was decided to proceed the same way as the LAI and to consider the 300 best performing solutions for $\mathrm{C}_{a b}$ estimations, since the RMSE plateau was always reached at this point. The lowest RMSE for summer 2013 was obtained with TCARI/OSAVI $\left(5.86 \mu \mathrm{g} / \mathrm{cm}^{2}\right)$. The lowest RMSEs for fall 2013 and summer 2014 were obtained with gNDVI $\left(3.86 \mu \mathrm{g} / \mathrm{cm}^{2}\right)$ and GM_94b $\left(2.89 \mu \mathrm{g} / \mathrm{cm}^{2}\right)$, respectively. MCARI2 performed very poorly for all dates, even more so than the RMSE and SAM criteria that at least showed acceptable performances for summer 2014. 
Table 7. Root mean square error (RMSE) of the various criteria at the retained $q$ value for LAI, $\mathrm{C}_{a b}$ and Car estimations of each date.

\begin{tabular}{|c|c|c|c|c|c|}
\hline & & $\begin{array}{l}\text { Fall } \\
2013\end{array}$ & $\begin{array}{c}\text { Summer } \\
2014\end{array}$ & $\begin{array}{c}\text { Summer } \\
2016\end{array}$ & All Dates \\
\hline & $q$ & 100 & 100 & 100 & 100 \\
\hline \multirow{6}{*}{$\begin{array}{c}\text { LAI } \\
{\left[\mathrm{m}^{2} / \mathrm{m}^{2}\right]}\end{array}$} & $\begin{array}{l}\text { RMSE } \\
\text { INT LAI }\end{array}$ & 0.61 & 0.61 & 0.63 & 0.62 \\
\hline & $\begin{array}{c}\text { SAM } \\
\text { INT LAI }\end{array}$ & 0.66 & 0.21 & 0.31 & 0.39 \\
\hline & NDVI & 0.17 & 0.23 & 0.24 & 0.22 \\
\hline & MSAVI2 & 0.18 & 0.24 & 0.29 & 0.25 \\
\hline & & $\begin{array}{c}\text { Summer } \\
2013\end{array}$ & $\begin{array}{l}\text { Fall } \\
2013\end{array}$ & $\begin{array}{c}\text { Summer } \\
2014\end{array}$ & All Dates \\
\hline & $q$ & 300 & 300 & 300 & 300 \\
\hline \multirow{8}{*}{$\begin{array}{c}\mathrm{C}_{a b} \\
{\left[\mu \mathrm{g} / \mathrm{cm}^{2}\right]}\end{array}$} & $\begin{array}{l}\text { RMSE } \\
\text { INT CAB }\end{array}$ & 12.45 & 15.36 & 6.36 & 11.92 \\
\hline & $\begin{array}{c}\text { SAM } \\
\text { INT CAB }\end{array}$ & 9.1 & 15.91 & 5.8 & 11.37 \\
\hline & MCARI2 & 10.44 & 14.38 & 10.57 & 12.15 \\
\hline & TCARI/OSAVI & 5.86 & 8.09 & 4.31 & 6.34 \\
\hline & Maccioni & 8.38 & 9.34 & 6.12 & 8.02 \\
\hline & gNDVI & 9.09 & 4.22 & 2.89 & 5.39 \\
\hline & GM_94b & 8.62 & 3.86 & 3.39 & 5.21 \\
\hline & $q$ & 400 & 400 & 400 & 400 \\
\hline \multirow{4}{*}{$\begin{array}{c}\text { Car } \\
{\left[\mu \mathrm{g} / \mathrm{cm}^{2}\right]}\end{array}$} & $\begin{array}{c}\text { RMSE } \\
\text { INT CAR }\end{array}$ & 0.58 & 1.14 & 2.94 & 1.34 \\
\hline & $\begin{array}{c}\text { SAM } \\
\text { INT CAR }\end{array}$ & 4.78 & 9.31 & 2.36 & 6.54 \\
\hline & R515/R570 & 5.74 & 4.32 & 2.74 & 4.01 \\
\hline & CRI & 2.87 & 3.83 & 1.91 & 2.89 \\
\hline
\end{tabular}

For Car, an optimal $q$ value was found when singling out the summer 2013 data and using the RMSE INT CAR criterion. However, at the other dates, the RMSE INT CAR criterion barely reached its plateauing value by $q=400$ (see Table 7 and Figure 8 c), so the 400 best performing solutions were considered for the multidate Car estimations. RMSE INT CAR presented the lowest RMSE for summer and fall 2013, while only presenting acceptable performances for summer 2014. Only RMSE INT CAR and CRI consistently showed acceptable performances, with a slight advantage for RMSE INT CAR. Both SAM INT CAR and R515/R570 had important RMSE variability over the three available dates.

\subsubsection{LAI Retrieval Performance Comparison}

Table 8 shows LAI retrieval performances when using the mean of the $q=100$ best solutions. Inversions based on NDVI and MSAVI2 differences performed equivalently in terms of RMSE (less than $0.25 \mathrm{~m}^{2} / \mathrm{m}^{2}$ ), bias, STDB, and $R^{2}$ (above 0.80 ). RMSE INT LAI performed the worse for all validation metrics, followed by SAM INT LAI.

Figure 9 shows that the highest LAI are slightly underestimated and vice versa, and that estimation uncertainties increase with LAI. Concerning low LAI points, only the fall 2013 points (blue) can be overestimated. No clear distinction in terms of performances is observed between other seasonal measurements. The global performance shows a $R^{2}$ of 0.8 and a total RMSE of $0.22 \mathrm{~m}^{2} / \mathrm{m}^{2}$. 


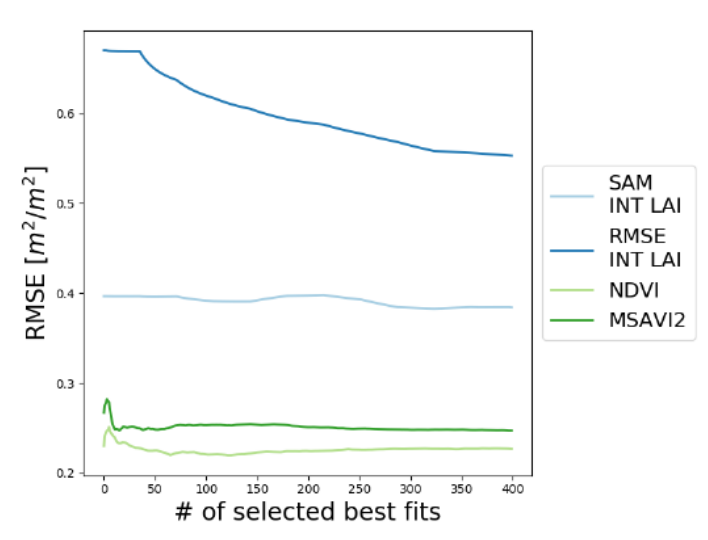

(a) LAI

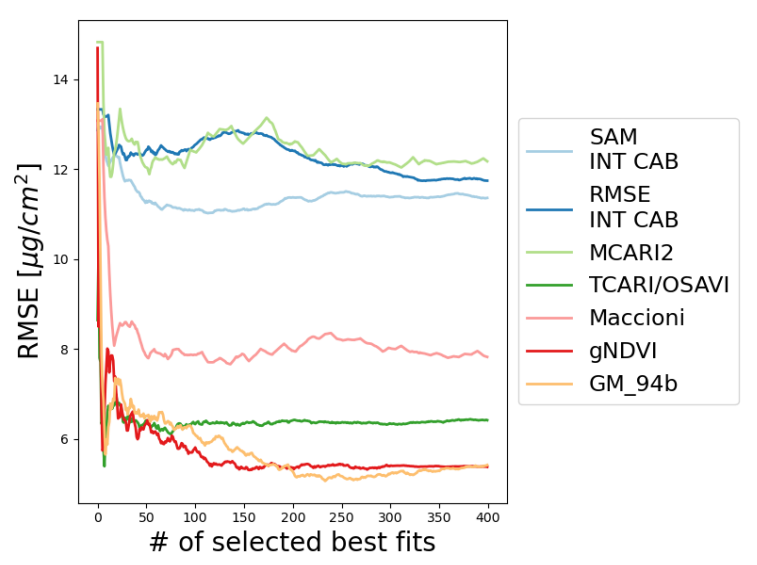

(b) $\mathrm{C}_{a b}$

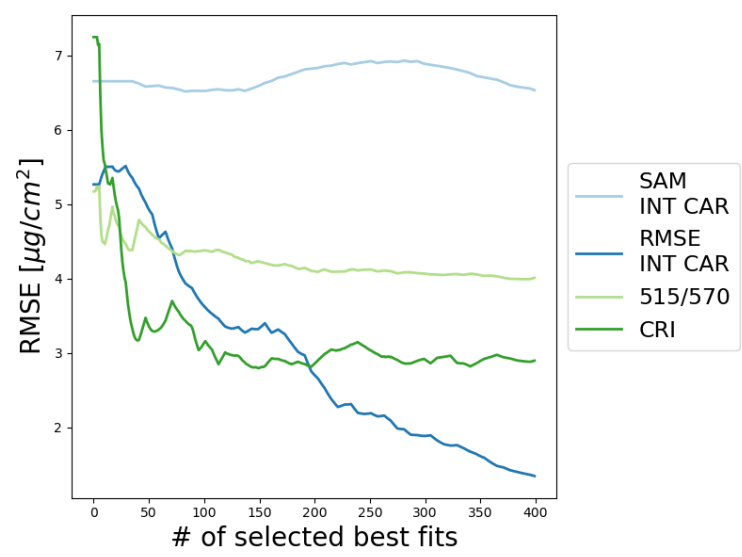

(c) Car

Figure 8. Influence of $q$ on the estimation RMSE for LAI (a), $\mathrm{C}_{a b}(\mathbf{b})$ and Car (c) using validation data from every date.

Table 8. Inversion methods performances for LAI estimation for $q=100$ over all dates available.

\begin{tabular}{ccccc}
\hline Method & $\begin{array}{c}\text { RMSE } \\
{\left[\mathbf{m}^{2} / \mathbf{m}^{2}\right]}\end{array}$ & $\begin{array}{c}\text { bias } \\
{\left[\mathbf{m}^{2} / \mathbf{m}^{2}\right]}\end{array}$ & $\begin{array}{c}\text { STDB } \\
{\left[\mathbf{m}^{2} / \mathbf{m}^{2}\right]}\end{array}$ & $\boldsymbol{R}^{\mathbf{2}}$ \\
\hline RMSE INT LAI & 0.62 & -0.49 & 0.29 & 0.38 \\
SAM INT LAI & 0.39 & -0.27 & 0.25 & 0.63 \\
NDVI & 0.22 & 0.07 & 0.18 & 0.80 \\
MSAVI2 & 0.25 & 0.14 & 0.17 & 0.81 \\
\hline
\end{tabular}

\subsection{3. $\mathrm{C}_{a b}$ and Car Retrieval Performance Comparison}

For $\mathrm{C}_{\mathrm{ab}}$ at $\mathrm{q}=300$, apart from DMCARI2, VI differences performed better than methods based on RMSE and SAM (Table 9). GM_94b is the overall best-performing VI, with the lowest RMSE, highest $\mathrm{R}^{2}$, and lowest STDB $\left(5.21 \mu \mathrm{g} / \mathrm{cm}^{2}, 0.73\right.$, and $3.38 \mu \mathrm{g} / \mathrm{cm}^{2}$, respectively), besting even soil-adjusted VI. When compared to field measurements from all dates, most GM_94b-estimated points are very close to the first bisector, and only one point (pink from summer 2013) is greatly underestimated (Figure 10a).

For Car, at $\mathrm{q}=400$, the best method is also clear: RMSE INT CAR is the only method to present a low RMSE, a low STDB, and a high $\mathrm{R}^{2}\left(1.34 \mu \mathrm{g} / \mathrm{cm}^{2}, 1.06 \mu \mathrm{g} / \mathrm{cm}^{2}\right.$ and 0.59 , respectively. See Table 9).

The RMSE INT CAR method showed the best performances overall, with estimated values very close to the first bisector (Figure 10b) for all seasons. 


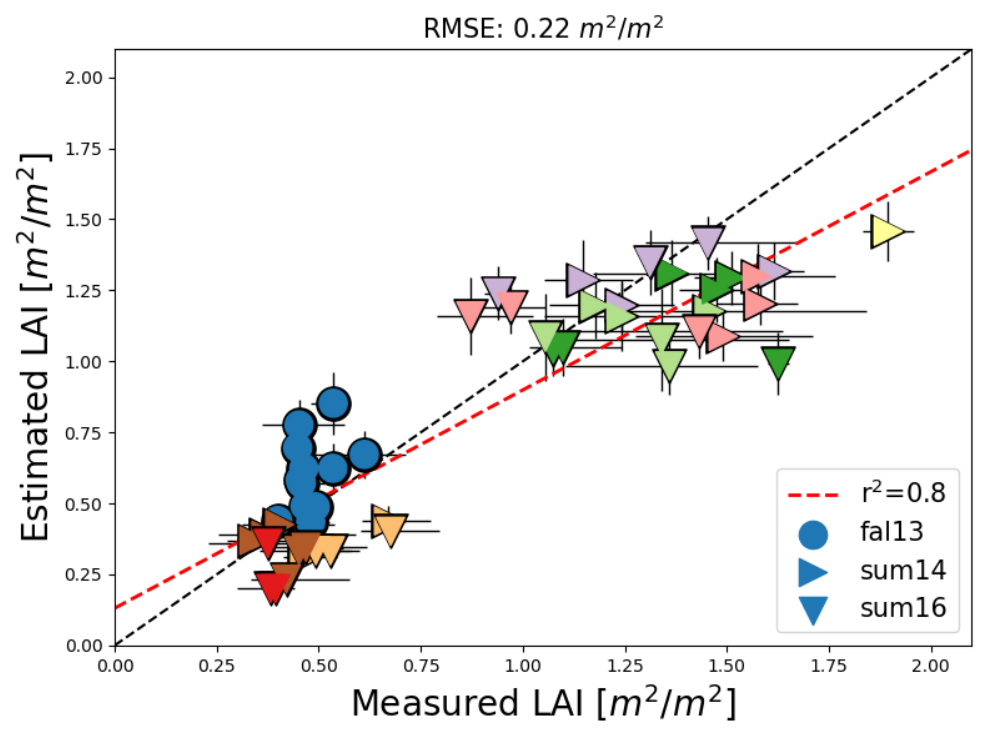

Figure 9. Estimated LAI using the $D_{N D V I}$ method versus measured LAI. Colors indicates the location within the site, see Figure 1. Error bars for the $y$-axis correspond to the estimation standard deviation, computed as the standard deviation of the first $q=100$ solutions. For the $\mathrm{x}$-axis, as each plot's measured LAI is the average of the computed LAI from each of the DHP of the plot, error bars correspond to the minimum and maximum values of each plot's DHP set.

Table 9. Inversion method performances for $C_{a b}(q=300)$ and Car $(q=400)$ estimations over all dates available.

\begin{tabular}{ccccc}
\hline Method & $\begin{array}{c}\text { RMSE } \\
{\left[\mu \mathrm{g} / \mathrm{cm}^{2}\right]}\end{array}$ & $\begin{array}{c}\text { bias } \\
{\left[\mu \mathrm{g} / \mathbf{c m}^{2}\right]}\end{array}$ & $\begin{array}{c}\text { STDB } \\
{\left[\mu \mathrm{g} / \mathbf{c m}^{2}\right]}\end{array}$ & $\boldsymbol{R}^{\mathbf{2}}$ \\
\hline C $_{a b}$ & & & & \\
\hline RMSE INT CAB & 11.92 & 8.99 & 5.21 & 0.14 \\
SAM INT CAB & 11.37 & 7.46 & 6.05 & 0.08 \\
MCARI2 & 12.15 & -5.05 & 8.62 & 0.01 \\
TCARI/OSAVI & 6.34 & 2.75 & 4.15 & 0.48 \\
Maccioni & 8.02 & 4.36 & 5.03 & 0.32 \\
gNDVI & 5.39 & -2.15 & 3.82 & 0.61 \\
GM_94b & 5.21 & -3.21 & 3.38 & 0.73 \\
\hline Car & & & & \\
\hline RMSE INT CAR & 1.34 & 0.79 & 1.06 & 0.59 \\
SAM INT CAR & 6.53 & 1.59 & 4.53 & 0.29 \\
R515/R570 & 4.01 & -1.26 & 3.74 & 0.26 \\
CRI & 2.89 & -0.2 & 2.1 & 0.05 \\
\hline
\end{tabular}



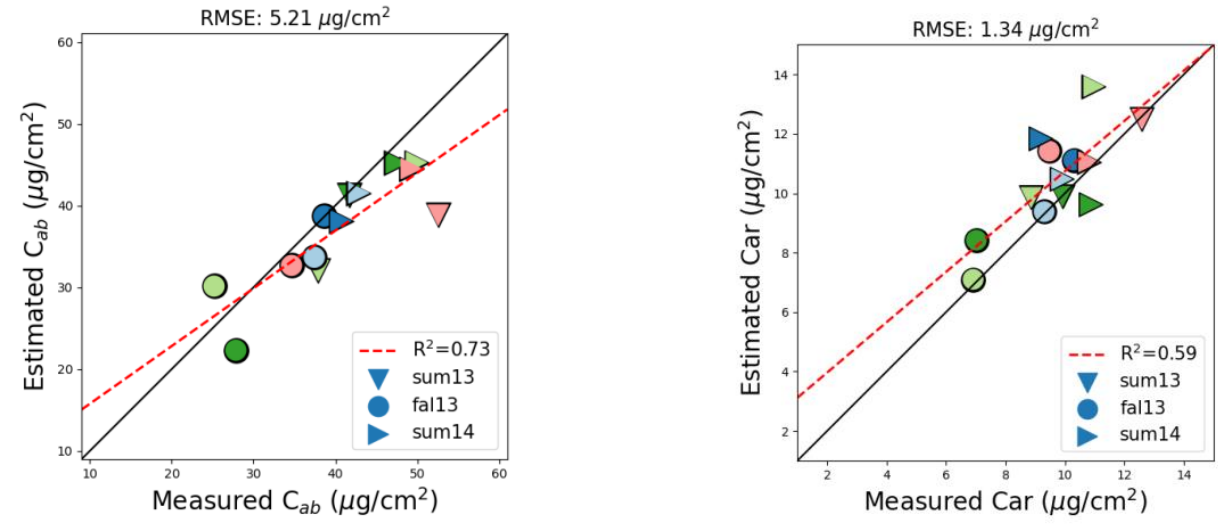

Figure 10. Measured versus estimated (a) leaf $C_{a b}$ using the $D_{G M \_94 b}$ method and (b) leaf Car using the RMSE INT CAR method. Colors indicate the location within the site, see Figure 1.

\subsection{LAI, $C_{a b}$ and Car Seasonal Monitoring}

In Appendix A are given estimation maps of Tonzi summer LAI and canopy $\mathrm{C}_{a b}$ and Car (LAI $\times$ foliar pigment content) from 2013 to 2018 (Figures A1-A3, in Appendix A respectively). These maps were computed using the best VI identified in Sections 3.3.2 and 3.3.3.

Focusing on years 2013 and 2015, estimated LAI and foliar $C_{a b}$ decreased from spring to fall (steady decrease from $0.9 \mathrm{~m}^{2} / \mathrm{m}^{2}$ and $38 \mu \mathrm{g} / \mathrm{cm}^{2}$ to $0.4 \mathrm{~m}^{2} / \mathrm{m}^{2}$ and $30 \mu \mathrm{g} / \mathrm{cm}^{2}$, respectively). Site LAI variations from summer to fall in 2013 and 2015 are greater than the estimations' STDB (Figure 11), while from $\mathrm{C}_{a r}$ only, summer to fall variations in 2015 are greater than the STDB (Figure 12). Concerning carotenoids, estimated variations are below the STDB and are therefore not remarkable.
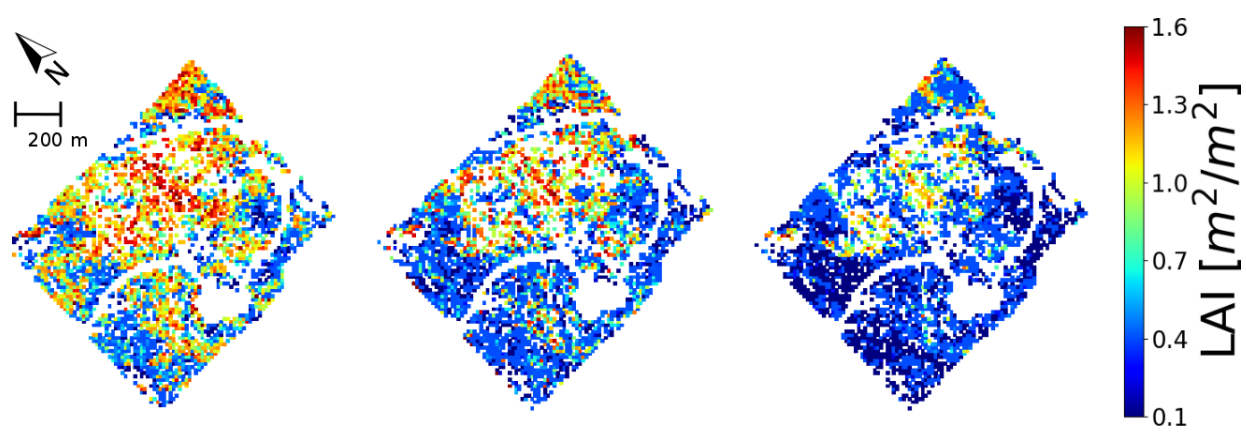

Figure 11. Estimated LAI over the year 2013. From left to right, spring, summer, and fall 2013.
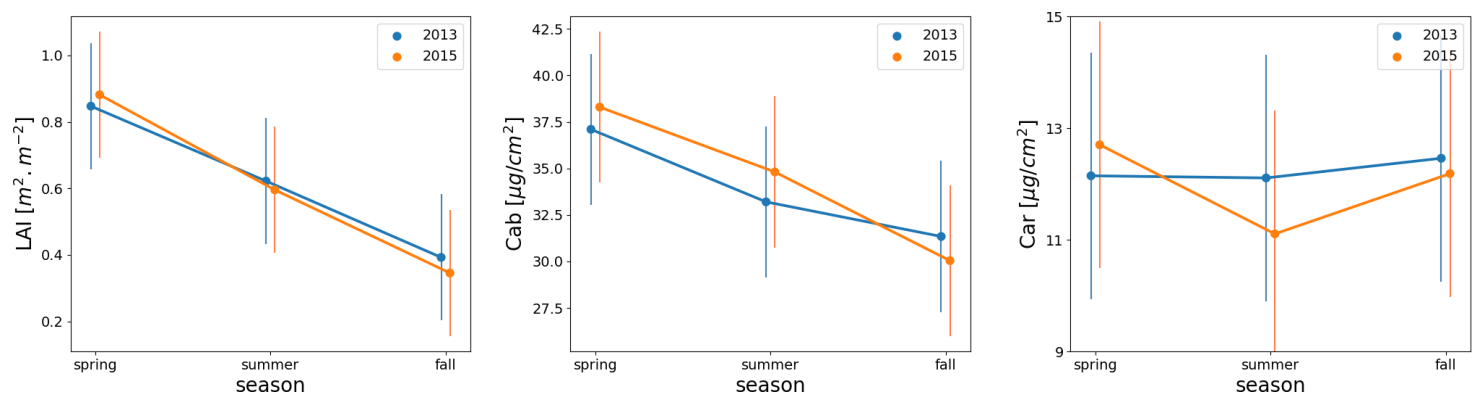

Figure 12. Mean site LAI, foliar $C_{a b}$, and foliar Car over the years 2013 and 2015. Bars indicate the STDB (standard deviation of the difference between estimated points and the regression line) of the best inversion methods. 


\section{Discussion}

\subsection{Limitations of the SFR for Low-LAI Sparse Forests Modeling within DART}

The forest representation chosen for this study aimed at minimizing the a priori knowledge necessary to monitor the Tonzi site. Trees modeled within the DART scenes had simplistic crown shapes and few nonphotosynthetic elements, as branches were not included. This has an impact on both LAI and $\mathrm{C}_{a b}$ estimations, as woody elements' influence on canopy reflectance can be important $[28,56]$ for heterogeneous and defoliated stands such as the Tonzi site. In particular, Malenovský et al. [28] and Widlowski et al. [32] showed that inclusion of woody elements within the DART canopies affects NIR reflectances for the resolutions considered in this study, which could explain the overestimated reflectances of the LUT in this spectral region (Figure 5).

These mismatches between computed and measured reflectances are such that some of the inversion methods tested in this study are not appropriate. Indeed, Table 6 shows that when considering the INT LAI and the INT CAB intervals, a large proportion of the AVIRIS-C images' pixels could not be explained by the LUTs. The consequence is that VI-based inversion criteria outperform those based on spectral intervals. While some VI may use reflectances in the NIR which are overestimated by DART (Figure 5), it appears that the overestimation effect is dampened as VI are less sensitive to differences in reflectance levels, and pixel-derived VIs are almost always within the boundaries of LUT-derived VIs.

The simplistic ground representation within the DART scenes, with a flat ground having a lambertian reflectance, may also be a source of errors, especially for the spring acquisitions, as important spatial variations of ground reflectance can be expected (see Sections 2.1 and 4.4). Unfortunately, such variation cannot be taken into account by the simple forest representation implemented in this study. A possible way to tackle this, though it would increase computation time, would be to introduce ground reflectance as another LUT parameter. However, the difficulty would be to make sure that most of the possible ground reflectances are captured by the LUT, which may not be an easy task when working with medium- to low-resolution images.

\subsection{Time Dependency of the Best Performing Inversion Method}

The objective was to be able to monitor the study site over multiple dates with or without available field data. As field data are usually scarce, inversion methods are often calibrated using data from only a single date. While this guarantees that the optimal method for this date has been found, the validity of extrapolations to images acquired at different times is not a given. Indeed, in Section 3.3's Table 7, TCARI/OSAVI, GM_94b and gNDVI indices could be identified as optimal depending on the date. However, when considering the complete dataset, which includes summer and fall data, GM_94b outperforms the others with a lower RMSE and higher $\mathrm{R}^{2}$ (Table 9). This highlights the need for multiple validation dates to properly select the inversion method if one aims to monitor canopies over time.

The number of best matches $q$ to keep when doing the LUT-based inversion also varied depending on the validation date, and a generalizable method to determine it was not found. There is still no clear methodology to determine this number. Banskota et al. [16] used three different values for the inversion ( $q=50$ when using 6 bands from AVIRIS-C images, $q=150$ when using their full spectrum, and $q=200$ when using Landsat images; LUT size: 115,000); Atzberger and Richter [64] only considered the best match when using 8 bands from CHRIS images (LUT size: 1,056,000); Weiss et al. [65] used $q=50$ when trying to inverse digital data sets (LUT size: 280,000); and Ferreira et al. [66] considered $q=20$ when using AISA images (LUT size: 3500). This is unfortunately not satisfactory, as much room is left for subjectivity and overfitting of the inversion method. 


\subsection{Assessment of LAI and Pigment Estimations Accuracy}

Even though the site LAI is very low (mean LAI is $0.8 \mathrm{~m}^{2} / \mathrm{m}^{2}$ and mean field points' LAI is 0.88 $\mathrm{m}^{2} / \mathrm{m}^{2}$ ), LAI estimations were encouraging. The LAI heterogeneity within the Tonzi site was captured, as for a given date, points from both low and high LAI parts of the site were correctly estimated. Seasonal variations were also visible, as LAI variations from summer to fall are clearly followed. Indeed, in Figure 9, blue and dark green points come from the same part of the site (see site map, Figure 1) but are from fall and summer, respectively. Estimation RMSE $\left(0.22 \mathrm{~m}^{2} / \mathrm{m}^{2}\right)$ is remarkably low, and nRMSE (RMSE divided by the mean field points' LAI) is 0.25 , quite similar to what can be obtained over a higher-LAI site: When estimating LAI over a Mediterranean grassland with a mean LAI of $2.87 \mathrm{~m}^{2} / \mathrm{m}^{2}$, Darvishzadeh et al. [67] obtained nRMSEs of 0.22 and 0.18 using statistical and RTM-inversion approaches, respectively.

$\mathrm{C}_{a b}$ estimation performances were in line with previous studies. Foliar chlorophylls content estimations $\left(\mathrm{RMSE}=5.21 \mu \mathrm{g} / \mathrm{cm}^{2}, R^{2}=0.73\right.$ ) are as good as what could be obtained over higher-LAI coniferous and deciduous sites in various studies (RMSE $=4.34 \mu \mathrm{g} / \mathrm{cm}^{2}, R^{2}=0.47$ [68]; $\mathrm{RMSE}=4.2 \mu \mathrm{g} / \mathrm{cm}^{2}$ [69]; RMSE $=8.1 \mu \mathrm{g} / \mathrm{cm}^{2}, R^{2}=0.40$ [29]). Carotenoid estimations also performed well with a low RMSE and high $\mathrm{R}^{2}\left(\mathrm{RMSE}=1.34 \mu \mathrm{g} / \mathrm{cm}^{2}, \mathrm{R}^{2}=0.59\right)$. This is similar to the values obtained by Zarco-Tejada et al. [57] using high-resolution imagery $(50 \mathrm{~cm})$ over vineyards (RMSE below $1.3 \mu \mathrm{g} / \mathrm{cm}^{2}$ and $\mathrm{R}^{2}$ of at most 0.46 when using the SAILH and the FLIGHT radiative transfer models).

A factor that could explain some estimation errors (and specifically the underestimation of the $\mathrm{C}_{\mathrm{ab}}$ summer 2013 pink point) is the assumption that the biochemistry measured on one tree can be considered representative of (i) the biochemistry of leaves that are sensed by AVIRIS-C (i.e., mostly top of canopy leaves) and (ii) the leaf biochemical content of all the trees within a pixel. While to address (i), attention was given to only collecting leaves on the sunlit part of the crown (see Section 2.2.2), it is not possible to confirm (ii) with the available field data, and a leap of faith must be made. There is therefore always an uncertainty concerning how representative validation data are with regards to their associated pixels.

\subsection{Challenges Concerning LAI, $\mathrm{C}_{a b}$ and Car Monitoring}

Concerning seasonal monitoring, while the QUDO phenophase is such that the site LAI and foliar $\mathrm{C}_{a b}$ should have presented a maximum in summer [70,71], Figure 12 showed a decrease from spring to fall. The most probable cause is that the C3 grass was not completely dead in May, as such a behavior is consistent with the results found by Stöckli et al. [72]. This induces a combined contribution of both the green grass and the QUDO vegetation layers in the spring. Even though grass reflectance was taken into account within DART models so that its biochemistry would not influence results, the pure soil pixels manually selected from the AVIRIS-C image for ground reflectance input within the DART model may have contained less green grass than other, non-pure-ground pixels. This would lead to erroneous estimations where green grass is present. As for both summer and fall, the grass is completely dry, which was not an issue for these seasons, and a LAI and foliar $\mathrm{C}_{a b}$ decrease was detected. Foliar carotenoid content was correctly found to be increasing between summer and fall for the two years with available fall images, which allows for a secondary validation of carotenoid estimations for this period. Concerning the high foliar Car during spring 2015, a possible cause would be the still-dying grass during the AVIRIS-C acquisition, due to problems similar to those already mentioned for LAI. Estimated LAI and $C_{a b}$ variations were greater than the estimation RMSE found in Sections 3.3.2 and 3.3.3, which gives confidence in the ability of the chosen methodology to monitor the site over summer and fall.

While this study used clear-sky images, clouds are often present in hyperspectral images. Obviously too thick clouds hide the ground, and cloud shadows can be hard to detect and correct for, but models to correct for thin cirrus presence in the $0.4-2.5 \mu \mathrm{m}$ spectral range exist [73-75] and could be used in case of operational use. 


\section{Conclusions}

Estimating canopy pigments and LAI using radiative transfer inversion is challenging in highly heterogeneous environments. This study investigated the ability of LUT-based inversion of AVIRIS-C medium resolution $(18 \mathrm{~m})$ hyperspectral images to estimate LAI and biochemical properties $\left(\mathrm{C}_{a b}\right.$, Car) of low-foliage open canopies (mean LAI: $0.82 \mathrm{~m}^{2} / \mathrm{m}^{2}$, mean CC: $47 \%$ ) in a woodland savanna. The methodology followed during this study used almost no a priori knowledge, so as to be able to monitor the study site in its entirety over multiple dates and obtain more general results. Various inversion criteria were tested, relying either on spectral intervals or hyperspectral vegetation indices. Results from very different site locations in terms of LAI, canopy cover, and tree structure were consistent and showed good accuracy for LAI and leaf $\mathrm{C}_{\mathrm{ab}}$ and Car retrieval. These results are further strengthened by the temporal aspect of the estimations, with validation done using both summer and fall data from various years. Estimated LAI and $\mathrm{C}_{a b}$ also showed a temporal pattern coherent with expected seasonal variations for dates when field data were not available.

This study found that the best inversion criterion for LAI estimation is: NDVI $\left(\frac{\rho_{0.833 \mu \mathrm{m}}-\rho_{0.677 \mu \mathrm{m}}}{\rho_{0.833 \mu \mathrm{m}}+\rho_{0.677 \mu \mathrm{m}}}\right)$ difference; for leaf $C_{a b}$ : GM_94b $\left(\frac{\rho_{0.750 \mu \mathrm{m}}}{\rho_{0.550 \mu \mathrm{m}}}\right)$ difference; and for leaf Car: RMSE between pixel and LUT reflectances over the $0.5-0 .-55 \mu \mathrm{m}$ spectral interval. These criteria showed results either comparable to or below previous studies done over denser canopies (RMSE for LAI: $0.22 \mathrm{~m}^{2} / \mathrm{m}^{2}$; for $\mathrm{C}_{a b}: 5.21 \mu \mathrm{g} / \mathrm{cm}^{2}$; for Car: $1.34 \mu \mathrm{g} / \mathrm{cm}^{2}$ ). Surprisingly, the vegetation indices presenting the best performances were not specifically designed to be soil-adjusted, which could indicate that the modeling within DART was sufficiently realistic when it came to ground reflectance, despite the ground being modeled as a lambertian surface with uniform reflectance.

The results demonstrated that medium resolution $(18 \mathrm{~m})$ hyperspectral imagery, combined with a 3D RTM only using a simple geometric representation of the canopy, is appropriate for the monitoring of vegetation bio-physicochemical parameters for low-LAI open broadleaved forests such as woodland savannas. In the future, the proposed estimation methodology should be further tested on another Californian site (San Joaquin Experimental Range, https: / / www.neonscience.org/field-sites / fieldsites-map/SJER) to confirm these results. Estimations should also be extended to leaf water content and leaf mass per area so as to have a complete overview of the forest health over time.

Author Contributions: Conceptualization, K.A., S.U., and X.B.; Data curation, T.M., K.A., and M.H.; Formal analysis, T.M.; Funding acquisition, K.A., S.U., and X.B.; Investigation, T.M.; Methodology, T.M. and K.A.; Project administration, S.U. and X.B.; Resources, K.A., M.H., and S.U.; Software, T.M.; Supervision, S.U. and X.B.; Validation, T.M.; Visualization, T.M.; Writing—original draft, T.M., K.A., and M.H.; Writing—review and editing, K.A., M.H., S.U., and X.B. All authors have read and agreed to the published version of the manuscript.

Funding: This research was funded by the Office Nationale d'Études et de Recherches Aérospatiales (ONERA) and by Région Occitanie.

Acknowledgments: The authors are grateful to the CSTARS team for collecting and processing the field data, and to NASA JPL from providing AVIRIS data (NASA grant No. NNX12AP08G). They also thank Jean-Philippe Gastellu-Etchegorry and Nicolas Lauret from CESBIO for their insight and help concerning the DART simulations. This research is also part of K. Adeline post-doctorate work funded by the National Aeronautics and Space Administration (NASA), Terrestrial Ecology program in preparatory research for the proposed HyspIRI satellite (S.L. Ustin PI, NASA grant No. NNX12AP87G, "Identification of plant functional types by characterization of canopy chemistry using an automated advanced canopy radiative transfer model").

Conflicts of Interest: The authors declare no conflict of interest. The funders had no role in the design of the study; in the collection, analyses, or interpretation of data; in the writing of the manuscript, or in the decision to publish the results. 
Appendix A

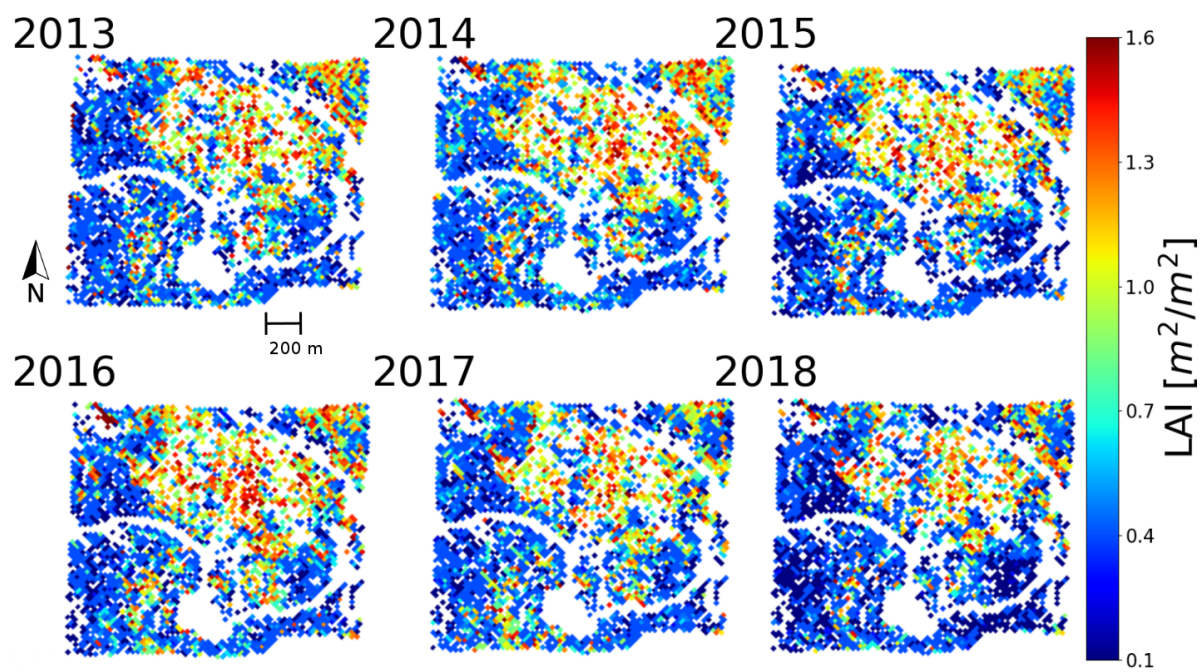

Figure A1. Estimated canopy LAI from 2013 to 2018. Areas in white were masked as they contained roads, buildings, water, too few QUDO and PISA trees or too many PISA trees.
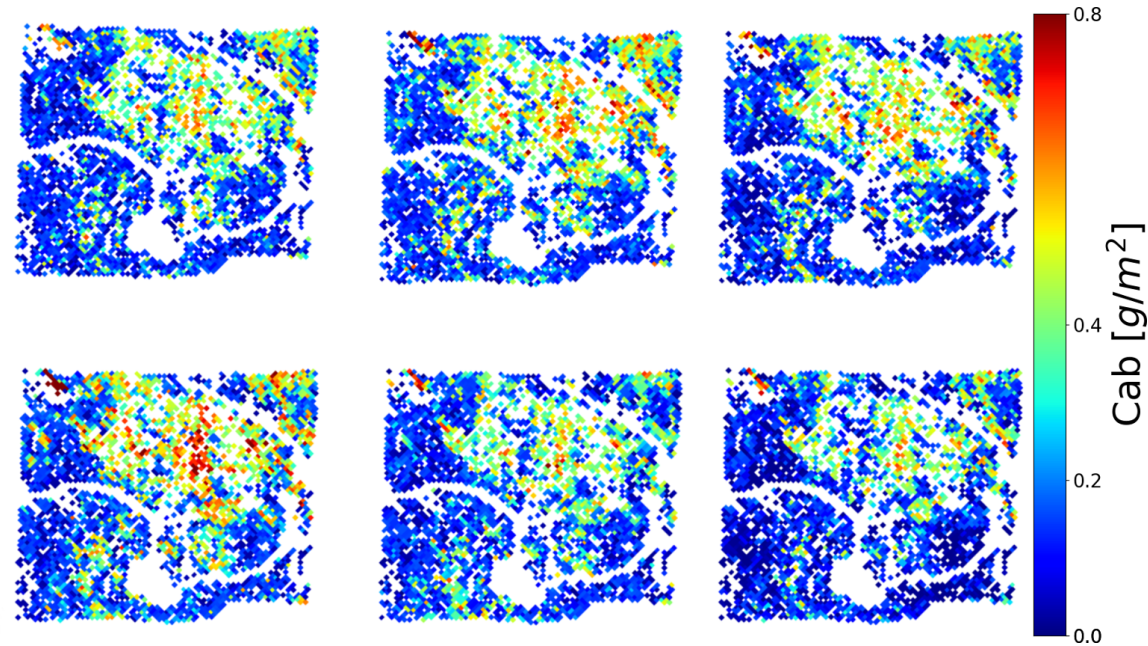

Figure A2. Estimated canopy $C_{a b}$ from 2013 to 2018. Areas in white were masked as they contained roads, buildings, water, too few QUDO and PISA trees or too many PISA trees.
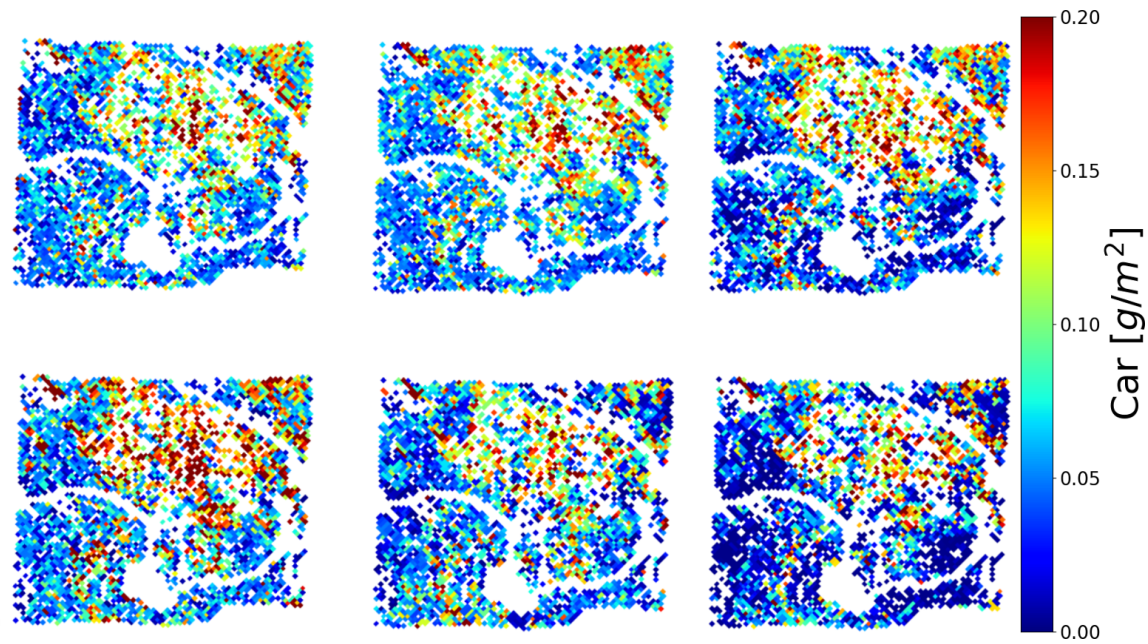

Figure A3. Estimated canopy Car from 2013 to 2018. Areas in white were masked as they contained roads, buildings, water, too few QUDO and PISA trees or too many PISA trees. 


\section{References}

1. Sala, O.E.; Chapin, F.S.; Armesto, J.J.; Berlow, E.; Bloomfield, J.; Dirzo, R.; Huber-Sanwald, E.; Huenneke, L.F.; Jackson, R.B.; Kinzig, A.; et al. Global biodiversity scenarios for the year 2100. Science 2000, 287, 1770-1774. [CrossRef] [PubMed]

2. Scarascia-Mugnozza, G.; Oswald, H.; Piussi, P.; Radoglou, K. Forests of the Mediterranean region: Gaps in knowledge and research needs. For. Ecol. Manag. 2000, 132, 97-109. [CrossRef]

3. Médail, F.; Diadema, K. Biodiversité végétale méditerranéenne et anthropisation: Approches macro et micro-régionales. Ann. Géogr. 2006, 651, 618-640. [CrossRef]

4. Underwood, E.C.; Viers, J.H.; Klausmeyer, K.R.; Cox, R.L.; Shaw, M.R. Threats and biodiversity in the mediterranean biome. Divers. Distrib. 2009, 15, 188-197. [CrossRef]

5. Sardans, J.; Peñuelas, J. Plant-soil interactions in Mediterranean forest and shrublands: Impacts of climatic change. Plant Soil 2013, 365, 1-33. [CrossRef] [PubMed]

6. Bengtsson, J.; Nilsson, S.G.; Franc, A.; Menozzi, P. Biodiversity, disturbances, ecosystem function and management of european forests. For. Ecol. Manag. 2000, 132, 39-50. [CrossRef]

7. Pereira, H.M.; Ferrier, S.; Walters, M.; Geller, G.N.; Jongman, R.H.; Scholes, R.J.; Bruford, M.W.; Brummitt, N.; Butchart, S.H.; Cardoso, A.C.; et al. Essential biodiversity variables. Science 2013, 339, 277-278. [CrossRef]

8. Jetz, W.; McGeoch, M.A.; Guralnick, R.; Ferrier, S.; Beck, J.; Costello, M.J.; Fernandez, M.; Geller, G.N.; Keil, P.; Merow, C.; et al. Essential biodiversity variables for mapping and monitoring species populations. Nat. Ecol. Evol. 2019, 3, 539-551. [CrossRef]

9. $\mathrm{Xu}, \mathrm{L} . ;$ Baldocchi, D.D. Seasonal trends in photosynthetic parameters and stomatal conductance of blue oak (Quercus douglasii) under prolonged summer drought and high temperature. Tree Physiol. 2003, 23, 865-877. [CrossRef]

10. Shipley, B.; Lechowicz, M.J.; Wright, I.; Reich, P.B. Fundamental trade-offs generating the worldwide leaf economics spectrum. Ecology 2006, 87, 535-541. [CrossRef]

11. Ma, S.; Baldocchi, D.D.; Mambelli, S.; Dawson, T.E. Are temporal variations of leaf traits responsible for seasonal and inter-annual variability in ecosystem CO2 exchange? Funct. Ecol. 2011, 25, 258-270. [CrossRef]

12. Krinner, G.; Viovy, N.; de Noblet-Ducoudré, N.; Ogée, J.; Polcher, J.; Friedlingstein, P.; Ciais, P.; Sitch, S.; Prentice, I.C. A dynamic global vegetation model for studies of the coupled atmosphere-biosphere system. Glob. Biogeochem. Cycles 2005, 19. [CrossRef]

13. Ustin, S.L.; Roberts, D.A.; Gamon, J.A.; Asner, G.P.; Green, R.O. Using Imaging Spectroscopy to Study Ecosystem Processes and Properties. BioScience 2004, 54, 523. [CrossRef]

14. Gascon, F.; Gastellu-Etchegorry, J.P.; Lefevre-Fonollosa, M.J.; Dufrene, E. Retrieval of forest biophysical variables by inverting a 3-D radiative transfer model and using high and very high resolution imagery. Int. J. Remote Sens. 2004. [CrossRef]

15. Homolová, L.; Janoutová, R.; Malenovský, Z. Evaluation of various spectral inputs for estimation of forest biochemical and structural properties from airborne imaging spectroscopy data. ISPRS Arch. 2016. [CrossRef]

16. Banskota, A.; Serbin, S.P.; Wynne, R.H.; Thomas, V.A.; Falkowski, M.J.; Kayastha, N.; Gastellu-Etchegorry, J.P.; Townsend, P.A. An LUT-Based Inversion of DART Model to Estimate Forest LAI from Hyperspectral Data. IEEE J. Sel. Top. Appl. Earth Obs. Remote Sens. 2015, 8, 3147-3160. [CrossRef]

17. Asner, G.P. Erratum: Biophysical and biochemical sources of variability in canopy reflectance. Remote Sens. Environ. 1998, 64, 234-253. [CrossRef]

18. Eriksson, H.M.; Eklundh, L.; Kuusk, A.; Nilson, T. Impact of understory vegetation on forest canopy reflectance and remotely sensed LAI estimates. Remote Sens. Environ. 2006, 103, 408-418. [CrossRef]

19. Eklundh, L.; Harrie, L.; Kuusk, A. Investigating relationships between landsat ETM+ sensor data and leaf area index in a boreal conifer forest. Remote Sens. Environ. 2001, 78, 239-251. [CrossRef]

20. Verrelst, J.; Camps-Valls, G.; Muñoz-Marí, J.; Rivera, J.P.; Veroustraete, F.; Clevers, J.G.; Moreno, J. Optical remote sensing and the retrieval of terrestrial vegetation bio-geophysical properties-A review. ISPRS J. Photogramm. Remote Sens. 2015, 108, 273-290. [CrossRef]

21. Baret, F.; Buis, S. Estimating Canopy Characteristics from Remote Sensing Observations: Review of Methods and Associated Problems. In Advances in Land Remote Sensing: System, Modeling, Inversion and Application; Liang, S., Ed.; Springer: Dordrecht, The Netherlands, 2008; pp. 173-201. [CrossRef] 
22. Gastellu-Etchegorry, J.P.; Demarez, V.; Pinel, V.; Zagolski, F. Modeling radiative transfer in heterogeneous 3-D vegetation canopies. Remote Sens. Environ. 1996, 58, 131-156. [CrossRef]

23. Adeline, K.; Roth, K.; Huesca, M.; Gastellu-Etchegorry, J.; Baldocchi, D.; Ustin, S. Spectral sensitivity of radiative transfer inversion for seasonal canopy pigments estimation from aviris data in a woodland savanna ecosystem. In Proceedings of the 2016 8th Workshop on Hyperspectral Image and Signal Processing: Evolution in Remote Sensing (WHISPERS), Los Angeles, CA, USA, 21-24 August 2016; pp. 1-5. [CrossRef]

24. Trumbore, S.; Brando, P.; Hartmann, H. Forest health and global change. Science 2015, 349, $814-818$. [CrossRef] [PubMed]

25. Le Maire, G.; François, C.; Soudani, K.; Berveiller, D.; Pontailler, J.Y.; Bréda, N.; Genet, H.; Davi, H.; Dufrêne, E. Calibration and validation of hyperspectral indices for the estimation of broadleaved forest leaf chlorophyll content, leaf mass per area, leaf area index and leaf canopy biomass. Remote Sens. Environ. 2008, 112, 3846-3864. [CrossRef]

26. Ali, A.M.; Skidmore, A.K.; Darvishzadeh, R.; van Duren, I.; Holzwarth, S.; Mueller, J. Retrieval of forest leaf functional traits from HySpex imagery using radiative transfer models and continuous wavelet analysis. ISPRS J. Photogramm. Remote Sens. 2016, 122, 68-80. [CrossRef]

27. Darvishzadeh, R.; Matkan, A.A.; Dashti Ahangar, A. Inversion of a radiative transfer model for estimation of rice canopy chlorophyll content using a lookup-table approach. IEEE J. Sel.Top. Appl. Earth Obs. Remote Sens. 2012, 5, 1222-1230. [CrossRef]

28. Malenovský, Z.; Martin, E.; Homolová, L.; Gastellu-Etchegorry, J.P.; Zurita-Milla, R.; Schaepman, M.E.; Pokorný, R.; Clevers, J.G.; Cudlín, P. Influence of woody elements of a Norway spruce canopy on nadir reflectance simulated by the DART model at very high spatial resolution. Remote Sens. Environ. 2008, 112, 1-18. [CrossRef]

29. Zarco-Tejada, P.J.; Miller, J.R.; Morales, A.; Berjón, A.; Agüera, J. Hyperspectral indices and model simulation for chlorophyll estimation in open-canopy tree crops. Remote Sens. Environ. 2004, 90, 463-476. [CrossRef]

30. Hernández-Clemente, R.; Navarro-Cerrillo, R.M.; Zarco-Tejada, P.J. Carotenoid content estimation in a heterogeneous conifer forest using narrow-band indices and PROSPECT+DART simulations. Remote Sens. Environ. 2012, 127, 298-315. [CrossRef]

31. Zarco-Tejada, P.J.; Hornero, A.; Beck, P.S.; Kattenborn, T.; Kempeneers, P.; Hernández-Clemente, R. Chlorophyll content estimation in an open-canopy conifer forest with Sentinel-2A and hyperspectral imagery in the context of forest decline. Remote Sens. Environ. 2019, 223, 320-335. [CrossRef]

32. Widlowski, J.L.; CÔté, J.F.; Béland, M. Abstract tree crowns in 3D radiative transfer models: Impact on simulated open-canopy reflectances. Remote Sens. Environ. 2014, 142, 155-175. [CrossRef]

33. Melendo-Vega, J.R.; Martín, M.P.; Pacheco-Labrador, J.; González-Cascón, R.; Moreno, G.; Pérez, F.; Migliavacca, M.; García, M.; North, P.; Riaño, D. Improving the performance of 3-D radiative transfer model FLIGHT to simulate optical properties of a tree-grass ecosystem. Remote Sens. 2018, 10, 2061. [CrossRef]

34. Janoutová, R.; Homolová, L.; Malenovský, Z.; Hanuš, J.; Lauret, N.; Gastellu-Etchegorry, J.P. Influence of 3D spruce tree representation on accuracy of airborne and satellite forest reflectance simulated in DART. Forests 2019, 10, 292. [CrossRef]

35. Baldocchi, D.D.; Xu, L.; Kiang, N. How plant functional-type, weather, seasonal drought, and soil physical properties alter water and energy fluxes of an oak-grass savanna and an annual grassland. Agric. For. Meteorol. 2004, 123, 13-39. [CrossRef]

36. Chen, Q.; Baldocchi, D.; Gong, P.; Dawson, T. Modeling radiation and photosynthesis of a heterogeneous savanna woodland landscape with a hierarchy of model complexities. Agric. For. Meteorol. 2008, 148, 1005-1020. [CrossRef]

37. Ma, S.; Baldocchi, D.D.; Xu, L.; Hehn, T. Inter-annual variability in carbon dioxide exchange of an oak/grass savanna and open grassland in California. Agric. For. Meteorol. 2007, 147, 157-171. [CrossRef]

38. Rich, P.M.; Wood, J.; Vieglais, D.A.; Burek, K.; Webb, N. Guide to HemiView: Software for Analysis of Hemispherical Photography; Delta-T Devices, Ltd.: Cambridge, UK, 1999.

39. Fang, H.; Baret, F.; Plummer, S.; Schaepman-Strub, G. An Overview of Global Leaf Area Index (LAI): Methods, Products, Validation, and Applications. Rev. Geophys. 2019, 57, 739-799. [CrossRef]

40. Lichtenthaler, H.K. Chlorophylls and Carotenoids: Pigments of Photosynthetic Biomembranes. Methods Enzymol. 1987, 148, 350-382. [CrossRef] 
41. Lichtenthaler, H.K.; Buschmann, C. Chlorophylls and Carotenoids: Measurement and Characterization by UV-VIS Spectroscopy. Curr. Protoc. Food Anal. Chem. 2001, 1, F4.3.1-F4.3.8. [CrossRef]

42. Green, R.O.; Eastwood, M.L.; Sarture, C.M.; Chrien, T.G.; Aronsson, M.; Chippendale, B.J.; Faust, J.A.; Pavri, B.E.; Chovit, C.J.; Solis, M.; et al. Imaging spectroscopy and the Airborne Visible/Infrared Imaging Spectrometer (AVIRIS). Remote Sens. Environ. 1998, 65, 227-248. [CrossRef]

43. Bo-Cai Gao.; Goetz, A.F. Column atmospheric water vapor and vegetation liquid water retrievals from airborne imaging spectrometer data. J. Geophys. Res. 1990, 95, 3549-3564. [CrossRef]

44. Schott, J.R.; Salvaggio, C.; Volchok, W.J. Radiometric scene normalization using pseudoinvariant features. Remote Sens. Environ. 1988, 26, 1-14. [CrossRef]

45. Karpouzli, E.; Malthus, T. The empirical line method for the atmospheric correction of IKONOS imagery. Int. J. Remote Sens. 2003, 24, 1143-1150. [CrossRef]

46. Hadjimitsis, D.G.; Clayton, C.R.; Retalis, A. The use of selected pseudo-invariant targets for the application of atmospheric correction in multi-temporal studies using satellite remotely sensed imagery. Int. J. Appl. Earth Obs. Geoinf. 2009, 11, 192-200. [CrossRef]

47. Haboudane, D.; Miller, J.R.; Pattey, E.; Zarco-Tejada, P.J.; Strachan, I.B. Hyperspectral vegetation indices and novel algorithms for predicting green LAI of crop canopies: Modeling and validation in the context of precision agriculture. Remote Sens. Environ. 2004, 90, 337-352. [CrossRef]

48. Chang, C.C.; Lin, C.J. LIBSVM: A Library for support vector machines. ACM Trans. Intell. Syst. Technol. 2011, 2. [CrossRef]

49. Kobayashi, H.; Baldocchi, D.D.; Ryu, Y.; Chen, Q.; Ma, S.; Osuna, J.L.; Ustin, S.L. Modeling energy and carbon fluxes in a heterogeneous oak woodland: A three-dimensional approach. Agric. For. Meteorol. 2012, 152, 83-100. [CrossRef]

50. Gastellu-Etchegorry, J.P.; Yin, T.; Lauret, N.; Cajgfinger, T.; Gregoire, T.; Grau, E.; Feret, J.B.; Lopes, M.; Guilleux, J.; Dedieu, G.; et al. Discrete anisotropic radiative transfer (DART 5) for modeling airborne and satellite spectroradiometer and LIDAR acquisitions of natural and urban landscapes. Remote Sens. 2015, 7, 1667-1701. [CrossRef]

51. Gastellu-Etchegorry, J.P.; Gascon, F.; Estève, P. An interpolation procedure for generalizing a look-up table inversion method. Remote Sens. Environ. 2003, 87, 55-71. [CrossRef]

52. Feret, J.B.; François, C.; Asner, G.P.; Gitelson, A.A.; Martin, R.E.; Bidel, L.P.; Ustin, S.L.; le Maire, G.; Jacquemoud, S. PROSPECT-4 and 5: Advances in the leaf optical properties model separating photosynthetic pigments. Remote Sens. Environ. 2008, 112, 3030-3043. [CrossRef]

53. Combal, B.; Baret, F.; Weiss, M.; Trubuil, A.; Macé, D.; Pragnère, A.; Myneni, R.; Knyazikhin, Y.; Wang, L. Retrieval of canopy biophysical variables from bidirectional reflectance using prior information to solve the ill-posed inverse problem. Remote Sens. Environ. 2003, 84, 1-15. [CrossRef]

54. Hill, J.; Buddenbaum, H.; Townsend, P.A. Imaging Spectroscopy of Forest Ecosystems: Perspectives for the Use of Space-borne Hyperspectral Earth Observation Systems. Surv. Geophys. 2019, 40, 553-588. [CrossRef]

55. Qi, J.; Chehbouni, A.; Huete, A.R.; Kerr, Y.H.; Sorooshian, S. A modified soil adjusted vegetation index. Remote Sens. Environ. 1994, 48, 119-126. [CrossRef]

56. Verrelst, J.; Schaepman, M.E.; Malenovský, Z.; Clevers, J.G.P.W. Effects of woody elements on simulated canopy reflectance: Implications for forest chlorophyll content retrieval. Remote Sens. Environ. 2010, 114, 647-656. [CrossRef]

57. Zarco-Tejada, P.J.; Guillén-Climent, M.L.; Hernández-Clemente, R.; Catalina, A.; González, M.R.; Martín, P. Estimating leaf carotenoid content in vineyards using high resolution hyperspectral imagery acquired from an unmanned aerial vehicle (UAV). Agric. For. Meteorol. 2013, 171-172, 281-294. [CrossRef]

58. Tucker, C.J. Red and photographic infrared linear combinations for monitoring vegetation. Remote Sens. Environ. 1979, 8, 127-150. [CrossRef]

59. Haboudane, D.; Miller, J.R.; Tremblay, N.; Zarco-Tejada, P.J.; Dextraze, L. Integrated narrow-band vegetation indices for prediction of crop chlorophyll content for application to precision agriculture. Remote Sens. Environ. 2002, 81, 416-426. [CrossRef]

60. Maccioni, A.; Agati, G.; Mazzinghi, P. New vegetation indices for remote measurement of chlorophylls based on leaf directional reflectance spectra. J. Photochem. Photobiol. B Biol. 2001, 61, 52-61. [CrossRef]

61. Smith, R.C.G.; Adams, J.; Stephens, D.J.; Hick, P.T. Forecasting wheat yield in a Mediterranean-type environment from the NOAA satellite. Aust. J. Agric. Res. 1995, 46, 113-125. [CrossRef] 
62. Gitelson, A.; Merzlyak, M.N. Spectral Reflectance Changes Associated with Autumn Senescence of Aesculus hippocastanum L. and Acer platanoides L. Leaves. Spectral Features and Relation to Chlorophyll Estimation. J. Plant Physiol. 1994, 143, 286-292. [CrossRef]

63. Gitelson, A.A.; Viña, A.; Verma, S.B.; Rundquist, D.C.; Arkebauer, T.J.; Keydan, G.; Leavitt, B.; Ciganda, V.; Burba, G.G.; Suyker, A.E. Relationship between gross primary production and chlorophyll content in crops: Implications for the synoptic monitoring of vegetation productivity. J. Geophys. Res. Atmos. 2006, 111. [CrossRef]

64. Atzberger, C.; Richter, K. Spatially constrained inversion of radiative transfer models for improved LAI mapping from future Sentinel-2 imagery. Remote Sens. Environ. 2012, 120, 208-218. [CrossRef]

65. Weiss, M.; Baret, F.; Myneni, R.B.; Pragnère, A.; Knyazikhin, Y. Investigation of a model inversion technique to estimate canopy biophysical variables from spectral and directional reflectance data. Agronomie 2000, 20, 3-22. [CrossRef]

66. Ferreira, M.P.; Féret, J.B.; Grau, E.; Gastellu-Etchegorry, J.P.; Shimabukuro, Y.E.; de Souza Filho, C.R. Retrieving structural and chemical properties of individual tree crowns in a highly diverse tropical forest with 3D radiative transfer modeling and imaging spectroscopy. Remote Sens. Environ. 2018, 211, $276-291$. [CrossRef]

67. Darvishzadeh, R.; Atzberger, C.; Skidmore, A.; Schlerf, M. Mapping grassland leaf area index with airborne hyperspectral imagery: A comparison study of statistical approaches and inversion of radiative transfer models. ISPRS J. Photogramm. Remote Sens. 2011, 66, 894-906. [CrossRef]

68. Zhang, Y.; Chen, J.M.; Miller, J.R.; Noland, T.L. Leaf chlorophyll content retrieval from airborne hyperspectral remote sensing imagery. Remote Sens. Environ. 2008, 112, 3234-3247. [CrossRef]

69. Delegido, J.; Alonso, L.; González, G.; Moreno, J. Estimating chlorophyll content of crops from hyperspectral data using a normalized area over reflectance curve (NAOC). Int. J. Appl. Earth Obs. Geoinf. 2010, 12, 165-174. [CrossRef]

70. Demarez, V.; Gastellu-Etchegorry, V.; Mougin, E.; Marty, G.; Proisy, C.; Dufrêne, E.; Ledantec, V. Seasonal variation of leaf chlorophyll content of a temperate forest. Inversion of the prospect model. Int. J. Remote Sens. 1999, 20, 879-894. [CrossRef]

71. Gara, T.W.; Darvishzadeh, R.; Skidmore, A.K.; Wang, T.; Heurich, M. Evaluating the performance of PROSPECT in the retrieval of leaf traits across canopy throughout the growing season. Int. J. Appl. Earth Obs. Geoinf. 2019, 83, 101919. [CrossRef]

72. Stöckli, R.; Rutishauser, T.; Baker, I.; Liniger, M.A.; Denning, A.S. A global reanalysis of vegetation phenology. J. Geophys. Res. Biogeosci. 2011, 116. [CrossRef]

73. Gao, B.C.; Kaufman, Y.J.; Han, W.; Wiscombe, W.J. Correction of thin cirrus path radiances in the 0.4-1.0 $\mu \mathrm{m}$ spectral region using the sensitive $1.375 \mu \mathrm{m}$ cirrus detecting channel. J. Geophys. Res. Atmos. 1998, 103, 32169-32176. [CrossRef]

74. Gao, B.C.; Li, R.R. Removal of thin cirrus scattering effects in landsat 8 OLI images using the cirrus detecting channel. Remote Sens. 2017, 9, 834. [CrossRef]

75. Salgado, S.; Poutier, L.; Briottet, X.; Mathieu, S. Validation of an empirical method for thin cirrus correction with Sentinel-2 data. In Proceedings of the SPIE 11152, Remote Sensing of Clouds and the Atmosphere XXIV, 111520 H, Strasbourg, France, 10 October 2019; p. 111520H. [CrossRef]

(C) 2019 by the authors. Licensee MDPI, Basel, Switzerland. This article is an open access article distributed under the terms and conditions of the Creative Commons Attribution (CC BY) license (http:/ / creativecommons.org/licenses/by/4.0/). 